\title{
Threshold-Enhanced PROMETHEE Group Decision Support under Uncertainties
}

\author{
Hsu-Shih Shih \\ Department of Management Sciences, Tamkang University, Tamsui, New Taipei 251301, Taiwan \\ Correspondence should be addressed to Hsu-Shih Shih; hshih@mail.tku.edu.tw
}

Received 11 January 2021; Revised 4 April 2021; Accepted 24 April 2021; Published 14 June 2021

Academic Editor: Anna M. Gil-Lafuente

Copyright (c) $2021 \mathrm{Hsu}$-Shih Shih. This is an open access article distributed under the Creative Commons Attribution License, which permits unrestricted use, distribution, and reproduction in any medium, provided the original work is properly cited.

As threshold determination is arduous when using PROMETHEE (Preference Ranking Organization METHod for Enrichment Evaluations) to make decisions, this study proposes a comprehensive PROMETHEE-based group decision support for covering the uncertainties of threshold determination, risk preferences, and the evaluation itself. To reduce the difficulty on threshold determination, it explicitly offers statistical aggregation of individuals' indifference and preference thresholds so as to obtain benefits from multiple sources of knowledge and experience. Three typical combinations are characterized that reflect conservative, balanced, and aggressive group preferences. We also derive 6 properties to illustrate the effects of threshold changes on preference changes. Despite variances among the individual rankings of alternatives, the rank differences within the group decisions do converge by the illustrative example. A larger interval of a conservative group preference generates more diverse ranks versus the other two group preferences. Moreover, PROMETHEE III has a power on managing inaccurate measurement. The introduction of S-shaped functions has the benefit of fitting behavioral decision making under uncertainty. Integrating these approaches together for a decision support, our proposal is less affected by rank variance and coherent with traditional group PROMETHEE under differentiated decision power.

\section{Introduction}

Preference Ranking Organization METHod for Enrichment Evaluations (PROMETHEE) [1] is one outranking approach among various multicriteria decision making (MCDM) techniques. Some advantages of it are no trade-offs among criteria, it preserves more decision information, and it is simple to use [2]. Its outranking relations represent flows leaving and entering through pairwise comparisons, reflecting indifference and preference thresholds. The PROMETHEE family consists of PROMETHEE I and II (for partial and complete rankings), PROMETHEE III (interval order) and IV (continuous) extensions, PROMETHEE V (for constrained multicriteria selection), and PROMETHEE VI (using interval values for human brain views). Software packages have employed a group decision extension of PROMETHEE to support visual analysis, denoted as Gaia (geometrical analysis for interactive aid) [3]. Though the family has achieved 2,393 scientific references up until
September 2020 [4], there is still a gap in processing uncertainties, especially under a group decision environment.

PROMETHEE III was developed to manage interval order by illustrating preference and indifference relations in comparison [1] and is able to deal with one type of uncertainties for an inaccurate measurement of performance. A second type of uncertainties concerns the difficult determination of thresholds in PROMETHEE. Another factor related to the risk preference of decision makers, or behavioral decision making under uncertainty, is formulated by an S-shaped value function of the prospect theory (PT) [5]. These uncertainties can be alleviated from the collective knowledge of individuals in a group [6], prompting this research to set up PROMETHEE-based group decision support for uncertainties.

One theoretical approach to group decision making (GDM) is the social choice theory, which seeks a synthesis of individual opinions, preferences, interests, or welfares to reach a collective decision, but there is no procedure for 
aggregating individual rankings into a group ranking without violating some reasonable assumptions. Aggregation is possible if compromise and agreement exist in the group [7]. Using this approach in PROMETHEE models should benefit from group members' contribution. Macharis et al. [8] first defined the group-supported PROMETHEE procedure using 3 stages. PROMETHEE I and II both combine individual net flows multiplied by their decision powers or weights of individuals, called global net flow. This concept has dominated other developments, such as that by [9] and Gaia visualization applications as well [10]. Aside from the consensus reaching process [11, 12], a lack of developments still exists over the effect of individual preference on the group decision. We believe that a comprehensive structure along the group process, accommodating the traditional group PROMETHEE procedure, will benefit DMs when dealing with a sophisticated decision in an uncertain environment.

Performance evaluation involves uncertainties, and being able to manipulate such data is highly useful. When looking at Mareschal's statistical data [4], most related works have handled uncertainties through fuzzy sets, such as Vavatsikos et al. [13], but Roy [14] mentioned multiple types of uncertainties could be a shortage of hands by fuzzy tools. In addition, the targeted problems formulated by fuzzy sets are defined in different preference structures compared to traditional approaches $[15,16]$. Another gap appears in the group decision environment, because there are not many works outside the structure of Macharis et al.'s groupsupported PROMETHEE procedure [8]. Goletsis et al. [17] extended some indices for measuring consensus among the group. We believe there should be other considerations for improvement of group decision support through the contribution of group members.

We thus target to extend the PROMETHEE-based group decision support in order to manage the abovementioned uncertainties. First, this study unravels the determination of thresholds via the aggregation of individuals' thresholds using statistical operations. Second, we handle uncertainty of parameter estimation by PROMETHEE III. Third, we modify the preference functions in PROMETHEE by an $S$-shaped value function to tackle the gains and the losses in value judgment, which can be considered as behavioral uncertainty. Finally, the processes for managing uncertainties are integrated into the proposed group decision support for a better decision.

The proposed group decision support enhances traditional group-supported PROMETHEE procedure [8] with the ability at processing a few uncertainties. It also has flexibility in coherence with traditional approaches by adjusting the corresponding parameters. We shall further demonstrate some properties illustrating the effects of threshold changes on preference changes to support the extension herein. The comprehensive structure helps decision makers (DMs) when dealing with a sophisticated decision in an uncertain environment.

The rest of the study runs as follows. Section 2 presents a literature review. Section 3 proposes the process of group decision making (GDM) in PROMETHEE. Section 4 evaluates recycling plants with sensitivity analyses. Section 5 discusses some issues in developing the group decision support. Section 6 gives conclusions.

\section{Literature Review}

We first review related works of group preference aggregation, group PROMETHEE, uncertain formulation, and behavioral influence in this section to support the development of our group decision support.

2.1. Group Preference Aggregation. In the PROMETHEE process, criterion weights and criterion thresholds are the basic inputs from the DM, depending on individual preferences. When the situation involves multiple DMs, these individual preferences should be aggregated into group preferences, which can support MCDM at any stage of the decision making process (see [6]). Assuming that a consensus would be reached, Dias and Clímaco [18] classified the participation of individuals at the input and output levels. At the input level, we want to provide input data, e.g., a criteria weight set, but it is outside the MCDM core process, which might obtain the preferences from teamwork rather than through a group decision process [19]. Analysis at the output level is also outside the MCDM process, as a social choice function aggregates individual ranks or does it via the Delphi technique in a soft fashion. We denote process level analysis as aggregation within the MCDM process. Shih [20] defined two types of external aggregation, preoperation (aggregating criteria rating and their weights) and postoperation (aggregating individuals' ranks), which match Dias and Clímaco's argument [18]. Table 1 classifies the examples.

PROMETHEE calculation generally needs inputs from indifference and preference thresholds. We know that the threshold can be obtained by an experiment or theoretical prediction if the criterion has a physical meaning, but it generally is a difficult task $[18,26]$. Roy et al. [27] revealed that the threshold in ELECTRE could have 3 forms: a constant, a proportion of a performance function, or a combination. Due to problems measuring the criteria, constant thresholds are used for outranking methods [9, 28]. Roy et al. [27] provided a guideline for the veto threshold $\geq$ the preference threshold $\geq$ the indifference threshold on any criterion in ELECTRE III. Rogers and Bruen [29] supplied a new interpretation of thresholds with physical meanings. Dias and Clímaco [18] dealt with imprecise information for groups in ELECTRE TRI and offered an interactive approach. Cantillo et al. [30] discussed how to accurately estimate indifferent thresholds for the information of a probability distribution in a stated choice. Achillas et al. [31] suggested an indifference threshold at 30\% of its preference threshold in ELECTRE III.

Frikha et al. [32] used mathematical programming for determining indifference and preference thresholds of PROMETHEE II through an interactive disaggregation approach, with the fixed values of thresholds being done in the interactive process via DMs' collaboration. Banamar and 
TABLE 1: Aggregation levels in MCDM by a group decision.

\begin{tabular}{|c|c|c|c|c|}
\hline \multirow{2}{*}{$\begin{array}{l}\text { Aggregation } \\
\text { level }\end{array}$} & \multicolumn{2}{|c|}{ Comparison of the classifications } & \multirow{2}{*}{ Example } & \multirow{2}{*}{ Note } \\
\hline & Dias and Clímaco [18] & Shih [20] & & \\
\hline Input level & $\begin{array}{l}\text { Transfer the inputs of } \\
\text { group members into the } \\
\text { group's input by an } \\
\text { operator }\end{array}$ & $\begin{array}{l}\text { External } \\
\text { aggregation with } \\
\text { preoperation }\end{array}$ & $\begin{array}{l}\text { (1) Aggregation of individual judgments } \\
\text { for AHP (Forman and Peniwati [21]) } \\
\text { (2) Weighted sum of subjective ratings on } \\
\text { some criteria by experts for TOPSIS } \\
\text { (Parkan and Wu [22]) }\end{array}$ & $\begin{array}{l}\text { Aggregation at this level can be } \\
\text { considered as teamwork } \\
\text { instead of group decision. }\end{array}$ \\
\hline
\end{tabular}

(1) Aggregation of individual priorities for AHP (Forman and Peniwati [21])

(2) Establishment of group separation Process level Not available $\quad \begin{gathered}\text { Internal } \\ \text { aggregation }\end{gathered}$

measure for TOPSIS (Shih et al. [19]) and considering differentiated decision power in the group (Shih [23])

(3) Weighting individual net flows to be the global evaluation for PROMETHEE (Macharis et al. [8])

(1) Aggregation of individual ranks from

Transfer the results of

Output level group members into the group's result by an operator
TOPSIS into a group rank by the Borda function (Shih et al. [24])

(2) Accumulation of the ranks of multijudges from PROMETHEE through

social welfare functions (Colson [25])
This level of aggregation is rather diverse, depending on the procedures of MCDM techniques. ggregation via

postoperation
Aggregation at this level operates by social choice functions for the group decision.
De Smet [33] made a temporal extension of PROMETHEE II. In their Step 4, they asked a DM to give his temporal indifference and preference thresholds in a dynamic environment. They then used the interpolation technique to set the thresholds with a few questions. Kourmpanis et al. [34] adopted the preference threshold of $10-30 \%$ for the difference between the maximum and the minimum values of each criterion, whereas the indifference threshold is $5-15 \%$ for that difference in PROMETHEE II. Demircioğlu and Ulukan [35] subsequently acted at their discretion and standardized the indifference and preference thresholds as one quarter and three quarters of the differences between the maximal and minimal performance values on each criterion, respectively, for PROMETHEE II in a group. Our study provides a new way to determine the fixed values of thresholds of PROMETHEE through group contribution.

2.2. Group PROMETHEE. Georgopoulou et al. [36] designed a group DSS to evaluate the scenarios of renewable energy sources (RES) penetration by PROMETHEE II. Though the group-supported many steps in the decision process as teamwork (see the explanation in Shih et al. [19]), i.e., a single output feeding into the DSS at each step, they added a negotiation procedure for consensus. Colson [25] employed the Argos multijudge and multicriteria group decision support system (GDSS) to evaluate OR's prize winner using ELECTRE I and II and utilized PROMETHEE I, II, and III with several social choice functions for supporting the deliberation process of the group. The DMs are able to see the collective rankings of the candidates by visual aid. Goletsis et al. [17] proposed a hybrid of ELECTRE III and PROMETHEE II in a group decision environment. Aside from the aggregation via weighting individuals' decision power as used by Macharis et al. [8], Goletsis et al. also proposed the personal satisfaction index (PSI), group satisfaction index (GSI), rest group satisfaction index (RGSI), and agreement index (AI) for checking group consensus to aid in further negotiation. Following the same fashion of Georgopoulou et al. [36], Haralambopoulos and Polatidis [37] employed PROMETHEE II for the evaluation of RES scenarios and promoted group consensus through sensitivity and weight interval analyses.

Morais and de Almeida [38] used PROMETHEE V for a leakage management strategy, employing the procedure given by Macharis et al. [8]. Silva et al. [39] took the same approach in dealing with rankings of watershed management options by PROMETHEE II and included a meeting for conflict resolution. Roozbahani et al. [40] utilized the precedence order of Yakowitz et al. [41] to obtain PROMETHEE II weights and exploited Goletsis et al.'s PSI and GSI [17] to seek group satisfaction when assessing water supply options. Morais et al. [42] proposed a threephase procedure (filter, veto, and choice) for group choice based on individual rankings, using PROMETHEE II to rate the alternative means of controlling environmental degradation. This method applies the upper and lower quartiles of alternatives, calculates the strength and weakness of alternatives, and selects the best alternative according to the highest difference between the strength and weakness sets. Ishizaka and Nemery [43] introduced a multiphased approach for location selection and partner grouping for pregraduation students looking for an apartment to share in London through PROMETHEE II. The last phase is the negotiation over location for each group. Behzadian et al. [44] employed PROMETHEE GDSS with PROMETHEE II to rank technical requirements of the house of quality. They utilized the Gaia plane for illustrating the conflicts, similarities, or independencies among the DMs' criteria, respectively. Tavana et al. [45] combined 
strengths, weaknesses, opportunities, and threats (SWOT) along with the Delphi technique for input into PROMETHEE GDSS in regards to pipeline planning.

After the essential contribution was proposed [8], Macharis et al. [10] further revisited their PROMETHEE GDSS and illustrated Gaia in greater detail for observing consensus and conflict within a group and its applications. Govindan et al. [46] prioritized green suppliers in a food supply chain by PROMETHEE I and II, conducted a group compromise rank by minimizing the distance from the individual ranks through linear programming, and validated the result by robustness analysis. Zivković et al. [47] used PROMETHEE-GAIA analysis to prioritize strategic goals in higher education organizations, as Gaia is able to provide information about potential conflicts of interests among DMs. He and $\mathrm{Xu}$ [11] developed a consensus framework for three preference orderings for PROMETHEE II. Abdelhadi et al. [48] established GDSS using a communication platform and PROMETHEE II, in which a negotiation process was included for the group. They claimed the system is flexible for communication through the use of web services. Although not the main focus herein, there are numerous recent developments for combining fuzzy sets. For instance, Zhang et al. [49] proposed an integrated group support with rough set theory and intuitionistic fuzzy sets by employing PROMETHEE II, thus claiming its effectiveness. Akram et al. [50] suggested a multicriteria GDM model for selecting green suppliers under bipolar fuzzy PROMETHEE I and II, in which the performance ratings of three DMs are averaged for the group's ratings. On the other hand, Soba et al. [51] made use of grey relation and PROMETHEE for the location selection of staffs in Turkey.

Table 1 lists the aggregation level of group decision supporting MCDM, while Table 2 presents the support contents and examples in PROMETHEE. The group support level is the MCDM's input, process, or output. The support content column includes the sureness of alternatives, criteria, criteria's thresholds and weights, decision power, posteriori enhancement, and consensus facilitation by the group. The latter two belong to the output level. The note column gives information on which PROMETHEE family is involved. The two examples at the input level, with external aggregation, are categorized as teamwork, and there is no explicit group decision. Aside from providing consensus-related indices for group facilitation, many studies have worked on posteriori enhancement to reach a compromise decision for the group. We observe that there is no comprehensive group support for the PROMETHEE family, including threshold determination by a group. Moreover, the capability for managing uncertainties does have some merits in group decision support. This is the gap our study is targeting to fill.

2.3. Uncertain Formulation. Roy [14] identified four sources of inaccuracy, uncertainty, and imprecision in decision models. The first three relate to data quality, and the last one involves the modeling process, which is out of this study's scope. Concerning data quality, PROMETHEE III ranks items based on preference and indifference intervals in order to prevent an inaccurate measurement on the criteria [53]. The interval matches the mean value of the net flows with the plus and minus of their standard deviation multiplied by a coefficient $\gamma$, i.e., an upper bound and a lower bound of indifferences. Though there are few studies involved, the value of the coefficient $\gamma$ depends on the applications or by DM. Tzeng and Huang [54] suggested that $\gamma=0.15$ globally. Shih et al. [55] found that the coefficient $\gamma$ cannot be so large as to avoid any difficulty at differentiating the ranks of alternatives. PROMETHEE III formulates an uncertain estimation on the indifferences of net flows, while PROMETHEE II is a special case of PROMETHEE III with $\gamma=0$. Greco et al. [56] proposed the PROMETHEE scoring method by considering the mean and the standard deviation of composite indicates, which could take on an equivalent role like PROMETHEE III, but their approach is not straightforward and their measure of probability distributions needs a number of Monte Carlo simulations.

2.4. Behavioral Influence. Another related issue is DM's risk preference in making a decision, e.g., risk averse, risk neutral, or risk seeking. We regard the prospect theory [5] as quite appropriate for formulation, because its S-shaped function can be formulated as an option preference function for PROMETHEE under uncertainty:

$$
v(x)= \begin{cases}(x-\phi)^{\alpha}, & \text { if } x \geq 0 \\ (-\lambda)(\phi-x)^{\beta}, & \text { if } x<0 .\end{cases}
$$

Here, $x$ is the monetary unit and $\varphi$ is the reference point. Tversky and Kahneman [5] suggested that $\alpha=\beta=0.88$, while $\lambda=2.25$.

The value function that passes through the reference point is S-shaped and asymmetrical, concave on the gains, and convex on the losses, with diminishing sensitivity. The magnitude of the loss, or the loss aversion coefficient, is 2.25 times that of the gain. Many experiments have been done to determine the parameters of the value functions. Table 3 organizes selected parameter pairs, which are generally obtained from specific DM responses to the given instances. As the reference point is critical in PT, we think that the pairwise comparisons in PROMETHEE mean both comparisons on attributes' performances mutually refer to each other. Since introducing the loss part of the S-shaped function will generally give different characteristics, we shall leave this for the Discussions section.

There are some research works on considering PT in the MCDM area. Korhonen et al. [63] examined choice behavior using an interactive reference direction approach by two experiments. Their results help interpret the phenomena of the additive utility difference model and PT. Salminen and Wallenius [64] checked PT in a deterministic MCDM context through experiments. The setting assumes a fixed reference alternative and equal weights for the criteria without considering probability weighting functions. The results support PT, and the explanatory power of PT outperforms the traditional value model. Along the same fashion, Salminen [65] proposed piecewise linear value 
TABLe 2: Typical support of a group decision to PROMETHEE.

\begin{tabular}{|c|c|c|c|}
\hline $\begin{array}{l}\text { Aggregation } \\
\text { level }\end{array}$ & Support content & Example & Note \\
\hline Input level & $\begin{array}{c}\text { Alternatives, criteria, performance, } \\
\text { and criteria's thresholds and } \\
\text { weights }\end{array}$ & $\begin{array}{l}\text { (1) Alternatives, thresholds, and weights predefined by a } \\
\text { decision group (Georgopoulou et al. [36]) } \\
\text { (2) Alternatives and criteria determined through the Delphi } \\
\text { method (Tavana et al. [45]) } \\
\text { (3) Performance ratings of DMs averaged to represent the } \\
\text { group's ratings (Akram et al. [50]) }\end{array}$ & $\begin{array}{l}\text { (1) For PROMETHEE } \\
\text { II, } \\
\text { (2) for PROMETHEE } \\
\text { II, } \\
\text { (3) for PROMETHEE } \\
\text { I and II }\end{array}$ \\
\hline Process level & Decision power & $\begin{array}{l}\text { Weighting individual net flows as the global evaluation } \\
\text { (Macharis et al. [8]) }\end{array}$ & For PROMETHEE II \\
\hline \multirow[t]{2}{*}{ Output level } & Posteriori enhancement & $\begin{array}{l}\text { (1) A negotiation procedure or meeting for consensus } \\
\text { (Georgopoulou et al. [36]) } \\
\text { (2) Several social choice functions for supporting the group } \\
\text { decision (Colson [25]) } \\
\text { (3) Sensitivity and weight interval analyses to promote } \\
\text { group consensus (Haralambopoulos and Polatidis [37]) } \\
\text { (4) The highest difference between upper and lower } \\
\text { positional counting of alternatives from individual ranking } \\
\text { (Morais et al. [52]) } \\
\text { (5) Group rank from minimizing the distance among the } \\
\text { individual ranks through linear programming (Govindan } \\
\text { et al. [46]) }\end{array}$ & $\begin{array}{c}\text { (1) For PROMETHEE } \\
\text { II, } \\
\text { (2) for PROMETHEE } \\
\text { I, II, and III, } \\
\text { (3) for PROMETHEE } \\
\text { II, } \\
\text { (4) for PROMETHEE } \\
\text { II, } \\
\text { (5) for PROMETHEE } \\
\text { I and II }\end{array}$ \\
\hline & Consensus facilitation & $\begin{array}{l}\text { Several consensus-related indices for checking the group } \\
\text { consensus (Goletsis et al. [17]) }\end{array}$ & For PROMETHEE II \\
\hline
\end{tabular}

TABLe 3: Some values used in the S-shaped functions.

\begin{tabular}{|c|c|c|c|c|c|}
\hline \multicolumn{3}{|c|}{ Parameter } & \multirow{2}{*}{ Data collected } & \multirow{2}{*}{ Source } & \multirow{2}{*}{ Note } \\
\hline$\alpha$ & $\beta$ & $\lambda$ & & & \\
\hline 0.88 & 0.88 & 2.25 & $\begin{array}{l}\text { The responses of graduate students to hypothetical choice } \\
\text { problems on money with or without probability }\end{array}$ & $\begin{array}{l}\text { Tversky and } \\
\text { Kahneman [5] }\end{array}$ & \\
\hline 0.725 & 0.717 & 2.04 & $\begin{array}{c}\text { The response of economics students to experimental } \\
\text { questions with hypothetical payoffs }\end{array}$ & Abdellaoui et al. [57] & Used in this study \\
\hline 0.37 & 0.59 & 1.51 & $\begin{array}{l}\text { The response of part-time postgraduate students for route } \\
\text { choice on trip scenarios with the lottery condition of time }\end{array}$ & $\begin{array}{l}\mathrm{Xu} \text { et al. [58] Ebert } \\
\text { and Wiesen [59] }\end{array}$ & \\
\hline 0.97 & 0.43 & 1.53 & $\begin{array}{l}\text { The response of students from various disciplines on } \\
\text { payoff of relevant lotteries with the subjects of online } \\
\text { recruiting system }\end{array}$ & & For high-order risk data \\
\hline 0.95 & 1.06 & 1.88 & $\begin{array}{l}\text { The response of Dutch residents on longevity and quality } \\
\text { of life through questions on the indifference between sure } \\
\text { outcomes and a risky prospect }\end{array}$ & Attema et al. [60] & $\begin{array}{l}\text { Estimation results of a power } \\
\text { model on sign-dependent } \\
\text { treatment }\end{array}$ \\
\hline 0.543 & 0.543 & 0.982 & $\begin{array}{l}\text { Data from Czech commercial database containing the } \\
\text { closing odds and results of } 82,667 \text { soccer matches from } 17 \\
\text { European leagues between } 1996 \text { and } 2014 \text { with a } \\
\text { calculation of winning probabilities }\end{array}$ & Krčál et al. [61] & No loss aversion \\
\hline 0.8088 & 0.8088 & 3.508 & $\begin{array}{l}\text { An online survey of 2,045 individuals in the U.S. on the } \\
\text { lottery questions of making energy-efficiency investments }\end{array}$ & Heutel [62] & $\begin{array}{l}\text { The mean values of the } \\
\text { parameters }\end{array}$ \\
\hline
\end{tabular}

functions to approximate the S-shaped value functions of PT. In the suggested process, the best solution so far is used as the reference alternative with an arbitrary set of weights in the beginning. Korhonen et al. [66] considered rational behavior in a multiattribute riskless choice and compared two strategies: (1) a win-win strategy with increasing and concave functions and decreasing marginal values; and (2) a tradeoff setting that is Tversky-Kahneman reference dependent and exhibits loss aversion. The results showed the DM's consistency in both strategies.
For directly connecting PT and PROMETHEE, Lerche and Geldermann [67] first integrated the elements of PT into PROMETHEE, employed Korhonen et al.'s piecewise linear function [63], and added an extra alternative as a reference. Shih et al. [55] followed the essence of PROMETHEE and TODIM $[68,69]$ by mutually referring to each other on the criteria performance of alternatives. Since the original form of S-shaped functions has the benefit of being studied greatly in the literature, we will exploit the proposal of Shih et al. [55] in our study. 
To sum up, our study offers the following contributions to the existing literature:

(i) Target a new way to determine the fixed values of thresholds of PROMETHEE through group contribution

(ii) Combine PROMETHEE III with S-shaped functions and group contribution on threshold determination for tackling three types of uncertainties

(iii) Provide a new framework of PROMETHEE-based group decision support and coherency with traditional group PROMETHEE

\section{Proposed Model}

This section illustrates the outrank relation with group thresholds and risky preference function.

3.1. Determination of Group Thresholds. In group PROMETHEE, two points arise. The first reflects collective group knowledge contributions to the process, and the second is how to straightforwardly process group contributions. Thresholds play an important role in outranking methods, but their determination is obscure. Collective knowledge could alleviate this burden by providing some clues for dealing with imprecise information in GDM under consensus [70]. The group inputs offer guidance for the threshold setting by simple statistics and are applicable to group PROMETHEE III. A manipulation of combinations of indifference and preference thresholds can also form different group preferences.

The values of indifference and preference thresholds commonly appear in ascending order, and outranking relations move progressively from indifference to strong preference [18]. If all group members supply inexact thresholds in such order, then we can manipulate them through statistical operations to obtain group thresholds. Following the central idea of PROMETHEE III, we consider an interval of both thresholds being formed by their means and standard deviations and define two sets of group thresholds with $K$ members, $k=1, \ldots, K$, on criterion $j$, $j=1, \ldots, n, \boldsymbol{p}_{j}=\left\{p_{j}^{1}, \ldots, p_{j}^{K}\right\}$ for a set of group preference thresholds and $\boldsymbol{q}_{j}=\left\{q_{j}^{1}, \ldots, q_{j}^{K}\right\}$ for the set of group indifference thresholds. The average of preference and indifference thresholds on criterion $j$ is defined as [71]

$$
\begin{aligned}
& \mu_{j}^{p}=\sum_{k=1}^{K} \frac{p_{j}^{k}}{K}, \\
& \mu_{j}^{q}=\sum_{k=1}^{K} \frac{q_{j}^{k}}{K} .
\end{aligned}
$$

We also present the corresponding standard deviations of the two thresholds as

$$
\begin{gathered}
\sigma_{j}^{p}=\sqrt{\sum_{k=1}^{K} \frac{\left(p_{j}^{k}-\mu_{j}^{p}\right)^{2}}{K-1}}, \\
\sigma_{j}^{q}=\sqrt{\sum_{k=1}^{K} \frac{\left(q_{j}^{k}-\mu_{j}^{q}\right)^{2}}{K-1} .}
\end{gathered}
$$

Similar to the concept of a control limit in quality control for group decision [72], we thus establish confidence intervals for preference and indifference thresholds of the group, $p_{j}^{*}$ and $q_{j}^{*}$, as

$\mu_{j}^{p}-z \sigma_{j}^{p} \leq p_{j}^{*} \leq \mu_{j}^{p}+z \sigma_{j}^{p}, \quad$ for preference confidence interval,

$\mu_{j}^{q}-z \sigma_{j}^{q} \leq q_{j}^{*} \leq \mu_{j}^{q}+z \sigma_{j}^{q}, \quad$ for indiffference confidence interval,

where $z$ is the standard normal deviate expressing how much percentages the confidence interval is under the normal distribution. For instance, the value of 1.96 is based on the fact of $95 \%$ of the area for a normal distribution.

The middle points and the upper and lower limits are our concern, and the group will make a selection based on its preferred limits with the corresponding $z$ value. Properties 1-3 in Appendix A provide a guide for the selection. An extra constraint should be embedded to meet a general rule $p_{j}^{*} \geq q_{j}^{*}, j=1, \ldots, n$; i.e., the group preference threshold is greater than or equal to the group indifference threshold.

The group outranking relation can thus be set. With a limited number of experts working on the decision, we deem a convenient form through combinations of the common operators of mean, maximum, and minimum. There are 9 combinations of these 3 operators for 2 thresholds, i.e., 3 by 3 . We choose 3 combined operations on these 2 thresholds of group members: mean-mean, maximum-minimum, and minimum-maximum; these 3 representative group preferences are, respectively, balanced, aggressive, and conservative. Figure 1 illustrates the group threshold changes. The minimum of indifference thresholds and the maximum of preference thresholds form a gradual slope based on

$$
q_{j}^{*}=\operatorname{Min}\left(q_{j}^{1}, \ldots, q_{j}^{K}\right) \text { and } p_{j}^{*}=\operatorname{Max}\left(p_{j}^{1}, \ldots, p_{j}^{K}\right) \text {. }
$$

Here, $k=1, \ldots, K$ for $K$ members in the group. This transition between two thresholds represents a cautious group preference. Figure 1(b) shows the group preference as being conservative or risk averse.

The maximum of indifference thresholds and the minimum of preference thresholds form a sharp slope, in which the group preference is aggressive or risk seeking. We thus set an extra constraint on the lower bound of the minimal value of preference thresholds to prevent an unfavorable preference order. The aggressive group preference is 


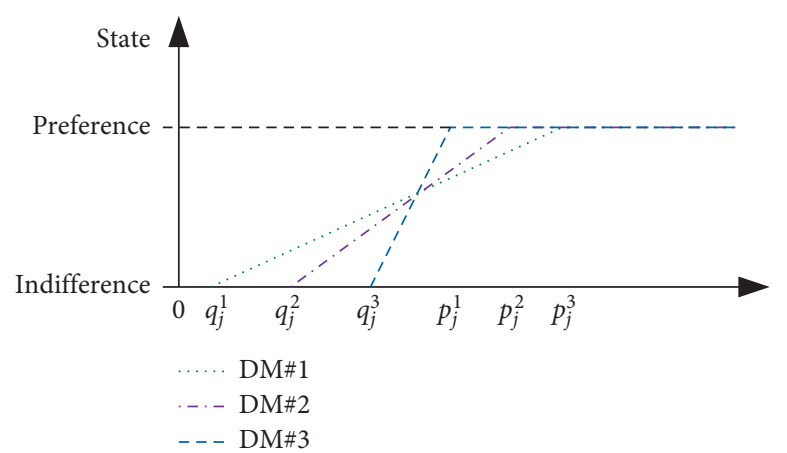

(a)

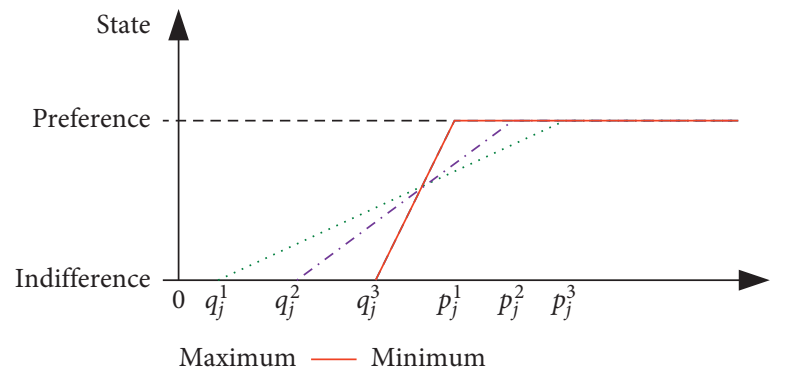

(c)

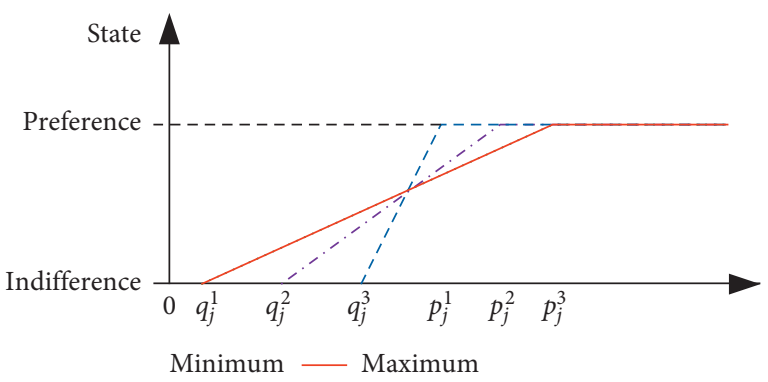

(b)

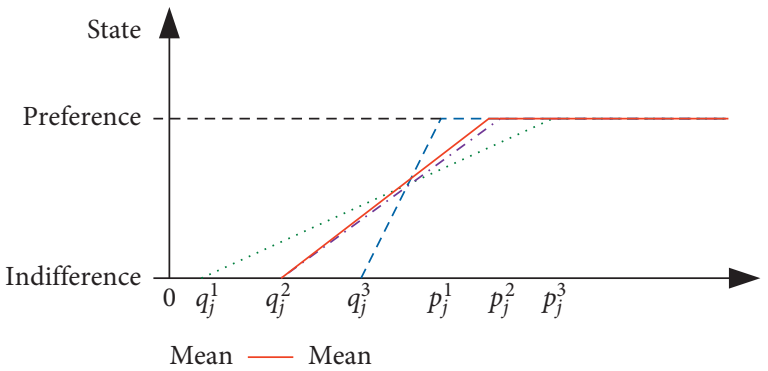

(d)

Figure 1: Three group preferences formed by the combinations of two thresholds. (a) Different values of indifference thresholds $q_{j}^{k}$ and preference thresholds $p_{j}^{k}$ on criterion $j, j=1, \ldots, n$ and $k=1,2$, and 3 for three decision makers. (b) Conservative group preference. (c) Aggressive group preference. (d) Balanced group preference.

$$
\left\{\begin{array}{l}
q_{j}^{*}=\operatorname{Min}\left(q_{j}^{1}, \ldots, q_{j}^{K}\right) \text { and } p_{j}^{*}=\operatorname{Max}\left(p_{j}^{1}, \ldots, p_{j}^{K}\right), \text { if } \underline{p_{j}} \geq \overline{q_{j}}, \\
q_{j}^{*}=\operatorname{Max}\left(q^{1}, q^{2}, \ldots, q^{K}\right)=p_{j}^{*}, \quad \text { if } \underline{p_{j}}<\overline{q_{j}} .
\end{array}\right.
$$

Here, $p_{j}=\operatorname{Min}\left(p_{j}^{1}, \ldots, p_{j}^{K}\right)$ and $\bar{q}_{j}=\operatorname{Max}\left(q_{j}^{1}, \ldots, q_{j}^{K}\right)$ on criterion $j$ with $K$ group members. If the latter case occurs, then the decision involves greater risk; i.e., Type II's function instead of Type V's for group PROMETHEE.

A balanced approach uses the central tendency of the thresholds. The mean or average operator describes the balanced group preference:

$$
q_{j}^{*}=\mu_{j}^{q} \text { and } p_{j}^{*}=\mu_{j}^{p} .
$$

It is common for $p_{j}^{*} \geq q_{j}^{*}$ in PROMETHEE; otherwise, $p_{j}^{*}=q_{j}^{*}$ for consistency.

Observe that Figure 1(a) shows the threshold information of three group members with different types of dashed lines; Figure 1(b) takes the minimum of the indifference thresholds and the maximum of the preference thresholds of the group members; Figure 1(c) takes the maximum of the indifference thresholds and the minimum of the preference thresholds of the group members; and Figure 1(d) takes the mean of the indifference thresholds and the preference thresholds of the group members. We can also see the transition interval between thresholds: conservative group preference $>$ balanced group preference $>$ aggregative group preference. This reflects group risk tolerance in which the outranking relation with a conservative group preference has the most tolerance among the 3, while that of an aggressive group preference has the least. Six properties illustrate positive or negative outcomes according to a drop or rise in threshold values in Appendix A. Since the change of DM's preference increases due to the movement of thresholds, discrimination ability is the highest with the aggregative group preference, while such ability in the conservative group preference is the least, because the change in DM's preference decreases. We further classify the proposed group aggregation as being at the input level and coherent with the traditional group PROMETHEE process.

\subsection{Preference Function Determination. PROMETHEE} provides 6 types of preference functions for comparison without risk. Shih et al. [55] generalized Type V function using S-shaped functions. Following the PT by Tversky and Kahneman [5], asymmetric preference functions $P_{j}\left(d_{j}\right)$ on criterion $j, j=1, \ldots, n$, can formulate a gain and loss for decision making under risk as 


$$
P_{j}\left(d_{j}\right)\left\{\begin{array}{l}
1, \quad \text { if } d_{j}>p_{j}, \\
\left(\frac{\left(d_{j}-q_{j}\right)}{\left(p_{j}-q_{j}\right)}\right)^{\alpha}, \quad \text { if } q_{j}<d_{j} \leq p_{j}, \\
0, \quad \text { if }-\left(\frac{q_{j}}{\lambda}\right) \leq d_{j} \leq q_{j}, \\
-\left(\frac{d_{j}+\left(q_{j} / \lambda\right)}{\left(-p_{j} q_{j} / \lambda\right)}\right)^{\beta}, \quad \text { if }-\left(\frac{p_{j}}{\lambda}\right) \leq d_{j} \leq\left(\frac{q_{j}}{\lambda}\right), \\
-1, \quad \text { if } d_{j}>-\left(\frac{p_{j}}{\lambda}\right),
\end{array}\right.
$$

where $d_{j}=g_{j}\left(a_{i}\right)-g_{j}\left(a_{i}\right)$ is the performance gap between alternatives $a_{i}$ and $a_{i}$ on criterion $j$, and $p_{j}$ and $q_{j}$ are the respective preference and indifference thresholds on criterion $j$.

We enhance a preference's discrimination capability by introducing an S-shaped function at the loss part, which is a sharp function within the transit interval of Figure 2. Equation (11) has a linear function form of Type $\mathrm{V}$ (Bouyssou et al. [73]) if we set $\alpha=\beta=\lambda=1$. Hence, the suggested function is a generalized form for the PROMETHEE family. In addition, the threshold setting at gain and loss parts is the same as Lerche and Geldmann [67] with more sensitive to the losses. Observe that we consider Abdellaoui et al.'s suggestion [57], which $\alpha=0.725, \beta=0.717$, and $\lambda=2.04$. However, there is no effect on preference change with small changes of thresholds through different sets of parameters. Please check Table 4 in below.

After the concepts are proposed, we suggest a comprehensive PROMETHEE group decision support under uncertainties as in Figure 3. There are $k, k=1,2, \ldots, K$, individual members in a group for making a decision. After understanding the decision problem, each DM will provide its preferences, including criterion weights, criterion thresholds, indifference coefficients (for PROMETHEE III only), and parameters of S-shaped functions, which could be categorized as the input level in Table 1. The group could think about whether or not all these parameters are considered as a group preference. In the former case, the group decision is characterized as teamwork. In the latter case, each DM will execute a flow calculation, and one can combine them by group weights for the decision power of each member, which is defined as a process level, for global evaluation. A group decision is then obtained. To manipulate uncertainty, group thresholds are from the input level, but the indifference coefficient and the parameter sets of an S-shaped function could be a fixed value or a couple of individual values, depending on the cases. However, when we acquire the individual ranks and aggregate the ranks into a group rank by a social choice function, the group support is then considered as an output level. Note that this decision support structure is also coherent with traditional group

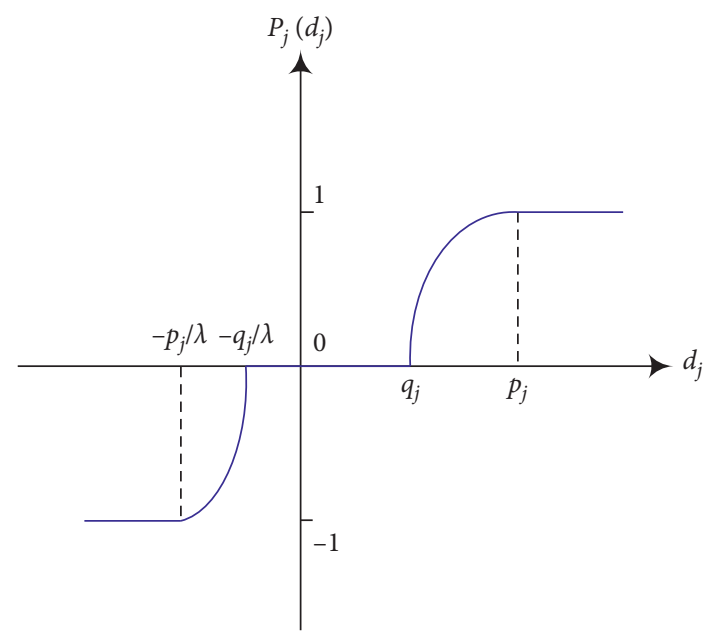

Figure 2: The generalized Type $\mathrm{V}$ function with a highlight of the gains and losses on criterion $j, j=1, \ldots, n$ [55].

PROMETHEE procedures because at the input level the parameters from the group are on demand. If teamwork is designed, then there is no blue box and group preference at the process level in this figure. We observe that Macharis et al.'s work [8] is marked with dotdashed lines, skipping the group preference at the input level. For simplicity of exhibition, we omit the part of group preference at the output level, which needs individual ranks for further processing as well as a negotiation or consensus procedure.

\section{Illustrative Case}

The Recycling Fund Management Board (RFMB) of the Environmental Protection Administration (EPA) of Taiwan collects recycling funds from manufacturers or importers and monitors waste materials flow through subsidies to the recycling industry and other sectors. A project has been set up to evaluate waste electrical and electronic equipment (WEEE) treatment plants, in order to rank and classify 15 local plants over five performance indices. Based on the evaluation, RFMB will pay an extra subsidy rate if a plant's performance is above the standard and lower rates if performance is fair or not good. RFMB also forces those plants performing under the standard to improve their recycling capability [20]. RFMB is seeking new evaluation technology, which forms the basis of our study.

Table 5 shows the performance data by five aspects of these 15 treatment plants [74]. A group of three experts performed an extended evaluation: an expert from RFMB, a university scholar, and a plant representative. Table 6 gives the thresholds and weights on the five aspects by group members, i.e., $q_{j}^{*}, p_{j}^{*}$, and $w_{j}^{*}$ on criterion $j, j=1, \ldots, 5$, respectively. Table 7 lists the corresponding values by the three group preferences, from equations (8)-(10), and group weights are the average of group members' values through agreement. Only constant thresholds are provided due to no direct physical sense for the composite indicators. We also utilize PROMETHEE III to cover the imprecise measurement in the evaluation. 
TABLE 4: Comparison of a preference change in the DM resulting from small changes of thresholds.

\begin{tabular}{|c|c|c|c|c|c|}
\hline \multicolumn{2}{|c|}{ Threshold change } & \multicolumn{3}{|c|}{ Preference change $\Delta P_{j}\left(d_{j}\right)$} & \multirow{3}{*}{ Note } \\
\hline \multirow{2}{*}{$\begin{array}{l}\text { Indifference } \\
\Delta q_{j}\end{array}$} & \multirow{2}{*}{$\begin{array}{c}\text { Preference } \\
\qquad \Delta p_{j}\end{array}$} & \multirow{2}{*}{ Type V function } & \multicolumn{2}{|c|}{ S-shaped function } & \\
\hline & & & Gain & Loss & \\
\hline 0.01 & --- & -0.026316 & -0.023256 & -0.023133 & Change in indifference threshold only \\
\hline-0.01 & --- & 0.023810 & 0.020753 & 0.020634 & \\
\hline--- & 0.02 & -0.045455 & -0.040394 & -0.040185 & Change in preference threshold only \\
\hline--- & -0.02 & 0.055556 & 0.048024 & 0.047738 & \\
\hline 0.01 & 0.02 & -0.071429 & -0.063973 & -0.063657 & Change in both thresholds in the same direction \\
\hline-0.01 & -0.02 & 0.078947 & 0.067845 & 0.067430 & \\
\hline 0.01 & -0.02 & 0.029412 & 0.025598 & 0.025450 & Change in both thresholds in the opposite directions \\
\hline-0.01 & 0.02 & -0.021739 & -0.019187 & -0.019084 & \\
\hline
\end{tabular}

Note. Other parameter sets in Table 3 keep the same properties.

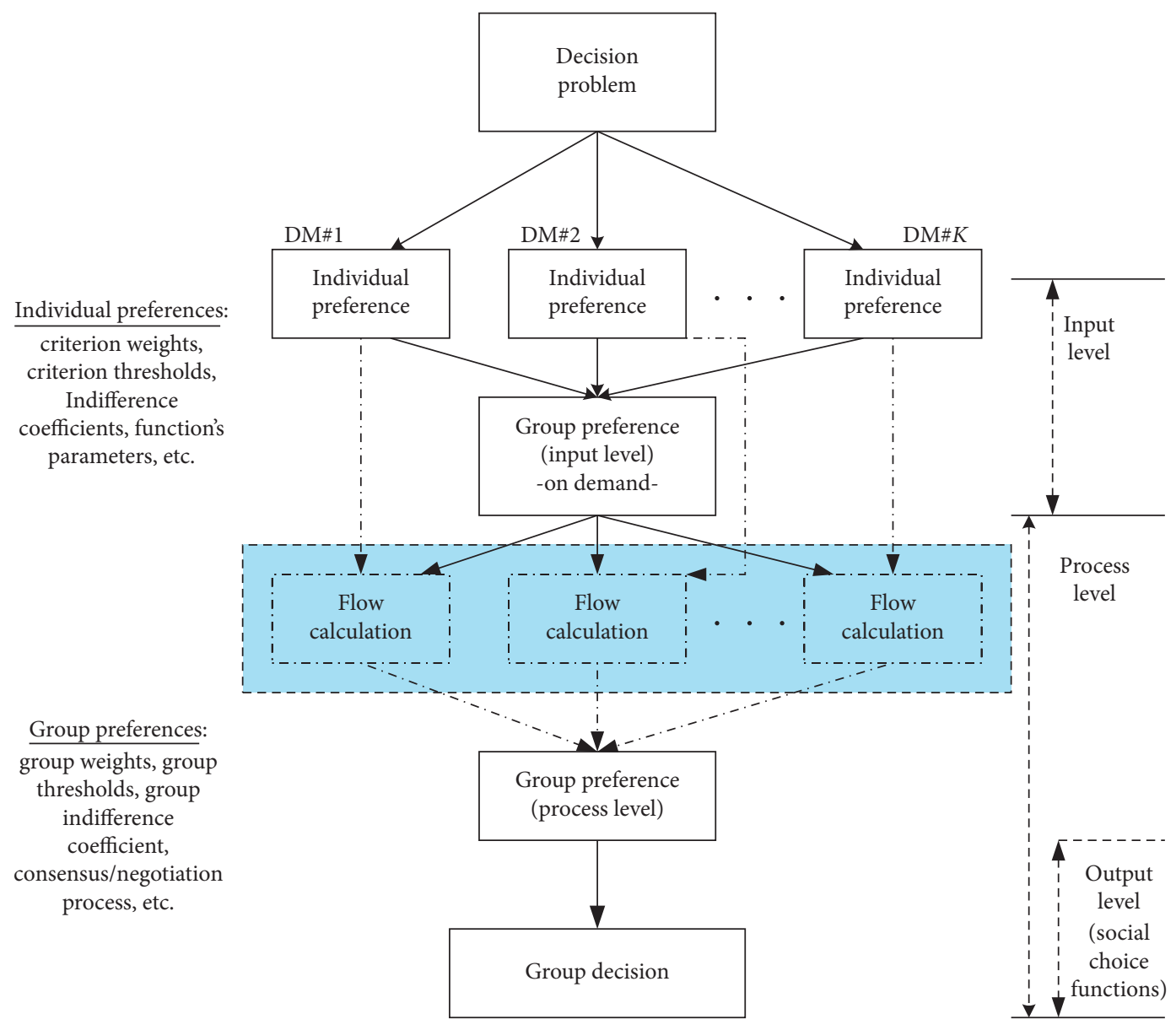

FIgUre 3: Proposed PROMETHEE-based group decision support.

Table 5: Performance measures of E-waste treatment plants in Taiwan.

\begin{tabular}{|c|c|c|c|c|c|}
\hline \multirow{2}{*}{ Plant } & \multicolumn{5}{|c|}{ Aspect } \\
\hline & Environment protection & Management system & Financial performance & Technology achievement & Social responsibility \\
\hline$A$ & 3.75 & 5.5 & 7.5 & 6.3 & 2.0 \\
\hline$B$ & 3.75 & 5.1 & 7.5 & 6.3 & 3.0 \\
\hline C & 4.25 & 4.75 & 8.5 & 7.6 & 3.5 \\
\hline$D$ & 3.25 & 5.0 & 5.25 & 2.2 & 1.0 \\
\hline E & 3.25 & 5.5 & 6.0 & 4.6 & 1.0 \\
\hline$F$ & 4.25 & 5.1 & 7.0 & 6.1 & 2.8 \\
\hline$G$ & 2.75 & 1.3 & 6.6 & 3.9 & 1.3 \\
\hline
\end{tabular}


Table 5: Continued.

\begin{tabular}{|c|c|c|c|c|c|}
\hline \multirow{2}{*}{ Plant } & \multicolumn{5}{|c|}{ Aspect } \\
\hline & Environment protection & Management system & Financial performance & Technology achievement & Social responsibility \\
\hline$H$ & 3.95 & 3.8 & 7.35 & 2.6 & 1.5 \\
\hline$I$ & 2.8 & 4.55 & 7.1 & 4.1 & 2.5 \\
\hline$J$ & 3.85 & 6.75 & 7.0 & 5.3 & 4.3 \\
\hline K & 4.1 & 4.0 & 5.6 & 8.6 & 2.0 \\
\hline$L$ & 3.25 & 2.75 & 6.8 & 4.1 & 1.0 \\
\hline$M$ & 4.25 & 5.5 & 5.05 & 5.9 & 2.0 \\
\hline$N$ & 3.25 & 4.75 & 6.6 & 3.6 & 4.0 \\
\hline$O$ & 2.8 & 3.5 & 6.6 & 4.6 & 3.0 \\
\hline
\end{tabular}

TABLE 6: Thresholds and criteria weights of the members of the group.

\begin{tabular}{|c|c|c|c|c|c|c|}
\hline $\begin{array}{l}\text { Group } \\
\text { member }\end{array}$ & Preference information & $\begin{array}{l}\text { Environment } \\
\text { protection }\end{array}$ & $\begin{array}{l}\text { Management } \\
\text { system }\end{array}$ & $\begin{array}{c}\text { Financial } \\
\text { performance }\end{array}$ & $\begin{array}{c}\text { Technology } \\
\text { achievement }\end{array}$ & $\begin{array}{c}\text { Social } \\
\text { responsibility }\end{array}$ \\
\hline \multirow{3}{*}{ RFMB } & \multirow{3}{*}{$\begin{array}{cc}\text { Thresholds } & \text { Indifference } \\
& q_{j}^{1} \\
\text { Preference } & p_{j}^{1} \\
\text { Criteria } & \text { weight } w_{j}^{1}\end{array}$} & 0.15 & 0.20 & 0.25 & 0.30 & 0.20 \\
\hline & & 0.35 & 0.50 & 0.60 & 0.80 & 0.40 \\
\hline & & 0.25 & 0.25 & 0.15 & 0.25 & 0.10 \\
\hline \multirow{3}{*}{ University } & \multirow{3}{*}{$\begin{array}{l}\text { Preference } p_{j}^{2} \\
\text { Criteria weight } w_{j}^{2}\end{array}$} & 0.25 & 0.30 & 0.40 & 0.45 & 0.25 \\
\hline & & 0.50 & 0.60 & 0.80 & 1.00 & 0.55 \\
\hline & & 0.4618 & 0.0898 & 0.0546 & 0.1853 & 0.2085 \\
\hline \multirow{3}{*}{ Industry } & \multirow{3}{*}{$\begin{array}{cc}\text { Thresholds } & \text { Indifference } \\
& q_{j}^{3} \\
& \text { Preference } p_{j}^{3} \\
\text { Criteria } & \text { weight } w_{j}^{3}\end{array}$} & 0.30 & 0.45 & 0.60 & 0.70 & 0.35 \\
\hline & & 0.60 & 0.90 & 1.10 & 1.20 & 0.70 \\
\hline & & 0.2479 & 0.1528 & 0.4351 & 0.0613 & 0.1029 \\
\hline
\end{tabular}

TABLE 7: Thresholds and criteria weights of the group with different group preferences.

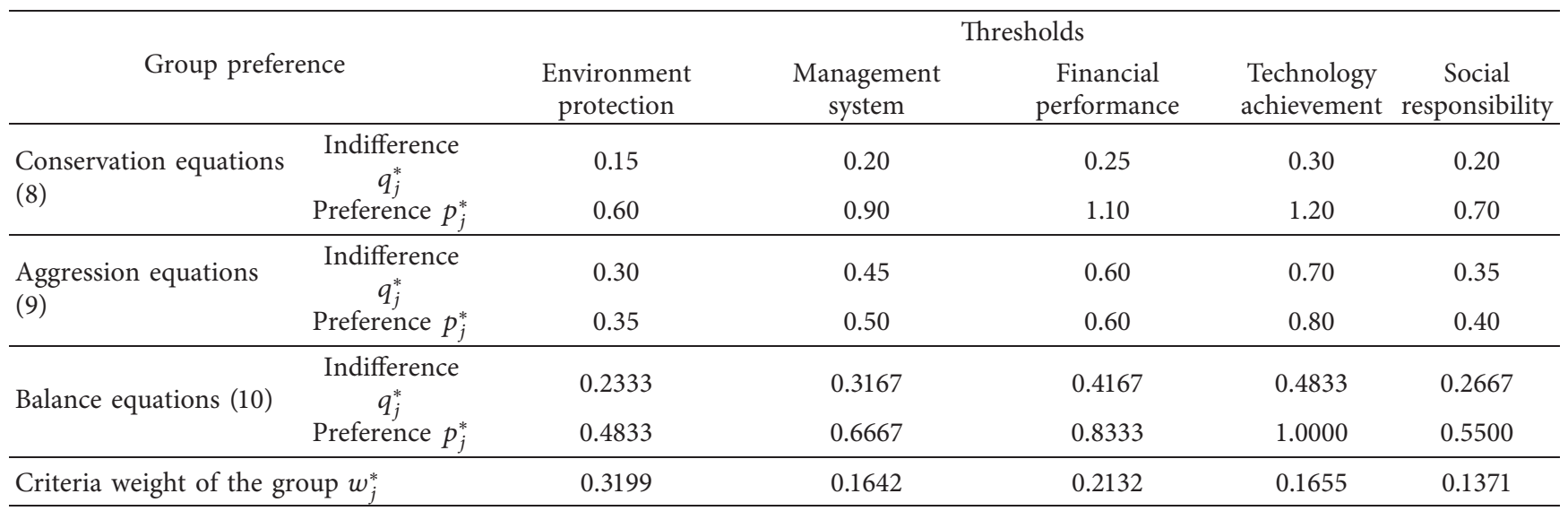

Note. $w_{j}^{*}$ takes the average value of all members' weights of the group.

PROMETHEE III yields an interval for indifference relations in addition to preference relations for evaluating performance measures. Le Téno and Mareschal [2] mentioned that the large interval will yield a large set of rankings which resulted in analytical burden. Here, the interval range is controlled by parameter $\gamma$, and we set the coefficient $\gamma=0.03$ after illustrating the effect on ranking to the group. To determine the parameters for the S-shaped function, we also demonstrate the parameter sets in Table 2 for the DMs, who accept Abdellaoui et al.'s suggestion [57] to describe their risky behavior for the PROMETHEE function.

Table 8 shows the rankings of the three DMs, where the ranks of the university scholar are considerably more diverse than those of the experts from RFMB and industry. The same table illustrates the ranks by the group using each of the three group preferences under equal decision power. The group rankings are quite similar, meaning the group decision has an offsetting effect among members. We next apply the 
TABLE 8: Ranks of plants by the single DM and the group by generalized PROMETHEE III with equal decision power.

\begin{tabular}{|c|c|c|c|c|c|c|c|c|c|c|c|c|c|c|c|c|}
\hline \multirow{2}{*}{\multicolumn{2}{|c|}{$\mathrm{DM}(\mathrm{s})$}} & \multicolumn{15}{|c|}{ Plants } \\
\hline & & $A$ & $B$ & $C$ & $D$ & $E$ & $F$ & $G$ & $H$ & $I$ & $J$ & K & $L$ & $M$ & $N$ & $O$ \\
\hline \multirow{3}{*}{$\begin{array}{l}\text { Single } \\
\text { DM }\end{array}$} & RFMB & $2(4)$ & $2(5)$ & $1(1)$ & $13(14)$ & $8(8)$ & $2(3)$ & $15(15)$ & $9(10)$ & $11(11)$ & $2(2)$ & $7(7)$ & $13(13)$ & $6(6)$ & $9(9)$ & $12(12)$ \\
\hline & University & $7(7)$ & $3(6)$ & $1(1)$ & $13(14)$ & $10(10)$ & $2(2)$ & 15 (15) & $8(8)$ & $10(12)$ & $3(3)$ & $3(5)$ & $13(13)$ & $3(4)$ & $8(9)$ & $10(11)$ \\
\hline & Industry & $2(4)$ & $2(3)$ & $1(1)$ & $15(15)$ & $11(13)$ & $2(5)$ & $14(14)$ & $6(6)$ & $7(8)$ & $2(2)$ & $10(10)$ & $11(12)$ & $7(9)$ & $7(7)$ & $11(11)$ \\
\hline \multirow{5}{*}{ Group } & Conservation & $4(5)$ & $4(4)$ & $1(1)$ & $14(14)$ & $10(10)$ & $2(2)$ & $15(15)$ & $8(8)$ & $10(11)$ & $2(3)$ & $7(7)$ & $13(13)$ & $6(6)$ & $9(9)$ & $12(12)$ \\
\hline & Aggression & $2(5)$ & $2(4)$ & $1(1)$ & $14(14)$ & $10(11)$ & $2(2)$ & $15(15)$ & $8(8)$ & $10(10)$ & $2(3)$ & $7(7)$ & $13(13)$ & $6(6)$ & $9(9)$ & $12(12)$ \\
\hline & Balance & $2(5)$ & $2(4)$ & $1(1)$ & $14(14)$ & $10(10)$ & $2(2)$ & $15(15)$ & $8(8)$ & $10(11)$ & $2(3)$ & $7(7)$ & $13(13)$ & $6(6)$ & $9(9)$ & $12(12)$ \\
\hline & $\begin{array}{l}\text { Borda } \\
\text { function }\end{array}$ & 5 & 2 & 1 & 14 & 10 & 2 & 15 & 8 & 10 & 4 & 7 & 13 & 6 & 9 & 12 \\
\hline & $\begin{array}{c}\text { Generalized } \\
\text { TODIM }\end{array}$ & 5 & 4 & 1 & 14 & 11 & 3 & 15 & 9 & 10 & 2 & 6 & 13 & 7 & 8 & 12 \\
\hline
\end{tabular}

Note. (1) The values in the parentheses are the ranks by PROMETHEE II. (2) Generalized PROMETHEE III means the use of the S-shaped preference function. (3) The ranks of generalized TODIM [75] using the group averaging weights.

Spearman ranking tests among the ranks generated by the three DMs and three group preferences. Because a couple of plants' ranks are the same, all correlation coefficients are greater than 0.9 , denoting that these ranks by individuals and with different group preferences are linearly correlated. The coefficients' values among the group are greater than those among the individuals, implying that the group model balances group member differences. We show the ranking results from PROMETHEE II in parentheses and list ranks by Borda count, a social choice function, in the table's last row. The results of generalized TODIM [75] are listed in the last row of Table 8 for comparison. The method considers S-shaped functions without thresholds, but the results look quite similar to others. Based on these evaluations, the performances of Plants $D, \mathrm{E}, G, \mathrm{I}, L$, and $\mathrm{O}$ are below standard and would receive a lower subsidy as a form of penalty; therefore, they should improve their treatment capability.

These different models yield similar ranks. As the effect from a group decision compromises individual decisions and thus group results converge, we now apply sensitivity analyses to further examine these effects. The first sensitivity analysis changes the weight of environmental protection by $\pm 50 \%$ of its original weight. Table 9 presents the results under a conservative group preference. We count the frequencies of rank changes on each alternative and sum over all alternatives to confirm whether the rankings are stable. The second analysis investigates the changes on both criteria weights and thresholds, to see how a single DM correlates to the group decision. Table 10 illustrates a spectrum of analysis results by alternative ranks from a single DM (from the university scholar) to the conservative group preference of the group, increasing each one by $10 \%$ of the values of the gap between a single DM and the group. Table 11 shows the combined outcomes of both analyses by numbers of rank changes. Although the outcomes do not appear to exhibit significant differences, we do see that the results of the conservative group preference provide more diverse ranks. There is no significant difference between the balanced and the aggressive group preferences in the case study. One could infer that a big interval between the thresholds of the conservative group preference provides many sets of rankings that will be risky for making a decision, and thus we need to use these thresholds carefully or use an interactive procedure for reassessing the thresholds to reduce possible risk [32]. Fortunately, we do not need to place much value on the other two group preferences in determining the thresholds at the individual level. Please see the contents of Appendix A about the phenomena.

We now investigate the effects of differentiated decision power on changes in the alternatives' ranks. Table 12 depicts the comparative results on the differentiated decision power of a single DM (from the university scholar) with a conservative group preference. We collect data on the numbers of rank changes on different group preferences and tabularize them in Table 11. The results from different settings look similar, meaning that the differentiated decision power does not generate a sufficiently different effect on final rankings. We also compare the proposed group decision to the results from traditional PROMETHEE with an S-shaped preference function. The numbers of rank changes under the approach of Macharis et al. [8] indeed provide diverse ranks, implying that our method has an advantage over their approach in rank preservation. We also list the results from their approach with the S-shaped function, which are promising for rank invariance. From the contents of Table 13, the use of S-shaped functions has a definite value for group PROMETHEE III.

\section{Discussions}

After proposing the group decision support, there are five issues left to be discussed in this section, including negative flows, weight assignment, consensus reaching, fuzzy process, and complexity analysis.

5.1. Negative Flows. The PROMETHEE's preference structure is based on measuring the deviation between the performance evaluation of any two alternatives on a particular criterion [3], covering six criteria for making decisions: usual criterion (Type I), quasi-criteria (Type II), criterion with linear preference (Type III), level-criterion (Type IV), criterion with linear preference and indifference area (Type V), and 
TABLE 9: Sensitivity analysis on the weight of environmental protection under conservative group preference of the group with equal decision power.

\begin{tabular}{|c|c|c|c|c|c|c|c|c|c|c|c|c|c|c|c|c|}
\hline \multirow{2}{*}{ Change of weight } & \multicolumn{15}{|c|}{ Alternatives } & \multirow{2}{*}{ Note } \\
\hline & $A$ & $B$ & C & $D$ & E & $F$ & $G$ & $H$ & $I$ & $J$ & $K$ & $L$ & $M$ & $N$ & $O$ & \\
\hline$-50 \%$ & 3 & 3 & 1 & 14 & 11 & 3 & 14 & 9 & 9 & 2 & 7 & 13 & 6 & 8 & 11 & \\
\hline$-40 \%$ & 3 & 3 & 1 & 14 & 11 & 3 & 14 & 9 & 9 & 2 & 7 & 13 & 6 & 8 & 11 & \\
\hline$-30 \%$ & 3 & 3 & 1 & 14 & 11 & 3 & 14 & 8 & 10 & 2 & 7 & 13 & 6 & 8 & 11 & \\
\hline$-20 \%$ & 2 & 2 & 1 & 14 & 10 & 2 & 14 & 8 & 10 & 2 & 7 & 13 & 6 & 8 & 12 & \\
\hline$-10 \%$ & 2 & 2 & 1 & 14 & 10 & 2 & 15 & 8 & 10 & 2 & 7 & 13 & 6 & 8 & 12 & \\
\hline $0 \%$ & 4 & 4 & 1 & 14 & 10 & 2 & 15 & 8 & 10 & 2 & 7 & 13 & 6 & 9 & 12 & Original weight \\
\hline $10 \%$ & 4 & 4 & 1 & 14 & 10 & 2 & 15 & 8 & 10 & 2 & 7 & 12 & 6 & 9 & 12 & \\
\hline $20 \%$ & 4 & 4 & 1 & 14 & 10 & 2 & 15 & 8 & 10 & 2 & 7 & 12 & 6 & 9 & 12 & \\
\hline $30 \%$ & 4 & 4 & 1 & 14 & 10 & 2 & 15 & 8 & 11 & 3 & 7 & 12 & 6 & 9 & 12 & \\
\hline $40 \%$ & 4 & 4 & 1 & 14 & 10 & 2 & 15 & 8 & 11 & 3 & 7 & 11 & 4 & 9 & 11 & \\
\hline $50 \%$ & 3 & 3 & 1 & 13 & 10 & 2 & 15 & 8 & 11 & 3 & 7 & 11 & 3 & 9 & 11 & \\
\hline Rank changes & 3 & 3 & 0 & 1 & 1 & 1 & 1 & 1 & 2 & 1 & 0 & 2 & 2 & 1 & 2 & 21 \\
\hline
\end{tabular}

Note. The total ranks of changes are 21 , whose values are listed in the rightmost cell of the last row.

TABLE 10: Sensitivity analysis on the weight and thresholds from a single DM (university) to the group under conservative group preference with equal decision power.

\begin{tabular}{|c|c|c|c|c|c|c|c|c|c|c|c|c|c|c|c|c|}
\hline \multirow{2}{*}{ Change of weight and thresholds } & \multicolumn{15}{|c|}{ Alternatives } & \multirow{2}{*}{ Note } \\
\hline & $A$ & $B$ & $C$ & $D$ & $E$ & $F$ & $G$ & $H$ & $I$ & $J$ & $K$ & $L$ & $M$ & $N$ & $O$ & \\
\hline $0 \%$ & 7 & 3 & 1 & 13 & 10 & 2 & 15 & 8 & 10 & 3 & 3 & 13 & 3 & 8 & 10 & Single DM \\
\hline $10 \%$ & 7 & 4 & 1 & 13 & 10 & 2 & 15 & 8 & 10 & 3 & 4 & 13 & 4 & 8 & 10 & \\
\hline $20 \%$ & 4 & 5 & 1 & 14 & 10 & 2 & 15 & 8 & 10 & 3 & 4 & 13 & 4 & 8 & 10 & \\
\hline $30 \%$ & 6 & 4 & 1 & 14 & 10 & 2 & 15 & 8 & 11 & 3 & 6 & 13 & 4 & 8 & 11 & \\
\hline $40 \%$ & 4 & 4 & 1 & 14 & 10 & 2 & 15 & 8 & 10 & 2 & 4 & 13 & 4 & 8 & 10 & \\
\hline $50 \%$ & 5 & 4 & 1 & 14 & 10 & 2 & 15 & 8 & 10 & 2 & 7 & 13 & 4 & 8 & 10 & \\
\hline $60 \%$ & 4 & 4 & 1 & 14 & 10 & 2 & 15 & 8 & 10 & 2 & 7 & 13 & 4 & 8 & 10 & \\
\hline $70 \%$ & 4 & 4 & 1 & 14 & 10 & 2 & 15 & 8 & 10 & 2 & 7 & 13 & 6 & 8 & 12 & \\
\hline $80 \%$ & 2 & 2 & 1 & 14 & 10 & 2 & 15 & 8 & 10 & 2 & 7 & 13 & 6 & 8 & 12 & \\
\hline $90 \%$ & 2 & 2 & 1 & 14 & 10 & 2 & 15 & 8 & 10 & 2 & 7 & 13 & 6 & 9 & 12 & \\
\hline $100 \%$ & 4 & 4 & 1 & 14 & 10 & 2 & 15 & 8 & 10 & 2 & 7 & 13 & 6 & 9 & 12 & Conservative group preference \\
\hline Rank changes & 5 & 3 & 0 & 1 & 0 & 0 & 0 & 0 & 2 & 1 & 4 & 0 & 2 & 1 & 3 & 22 \\
\hline
\end{tabular}

Note. The total ranks of changes are 22 , whose value is illustrated in the rightmost cell of the last row.

TABle 11: Comparison on the total ranks of changes for group PROMETHEE III with equal decision power.

\begin{tabular}{|c|c|c|c|c|c|}
\hline \multirow{2}{*}{\multicolumn{2}{|c|}{ Sensitivity analysis }} & \multicolumn{3}{|c|}{ Group preference } & \multirow{2}{*}{ Note } \\
\hline & & Conservation & Balance & Aggression & \\
\hline Change of weight on environme & ntal criterion & 21 & 16 & 17 & Change of weights by $\pm 50 \%$ of the original weight \\
\hline \multirow{3}{*}{$\begin{array}{l}\text { Change of weight and } \\
\text { thresholds from a single DM to } \\
\text { the group }\end{array}$} & $\begin{array}{c}\text { DM \#1 } \\
(\mathrm{RFMB})\end{array}$ & 8 & 10 & 10 & \multirow{3}{*}{$\begin{array}{l}\text { Changes of both weights and thresholds from a } \\
\text { single DM to the group incrementally by } 10 \% \text { for } \\
\text { each gap. }\end{array}$} \\
\hline & $\begin{array}{c}\text { DM \#2 } \\
\text { (university) }\end{array}$ & 22 & 20 & 20 & \\
\hline & $\begin{array}{c}\text { DM \#3 } \\
\text { (industry) }\end{array}$ & 23 & 17 & 17 & \\
\hline
\end{tabular}

Gaussian criterion (Type VI) [53]. The above six functions only count the positive difference on the one side and give a value of zero for an inferior comparison. After introducing the S-shaped functions of PT [5], the negative flows are counted for the evaluation. Apart from ordinal characteristics of Types I, II, and IV, we choose the general form of Type V for the modification. The loss part of the S-shaped function has a negative flow in the modified process and produces a large difference due to risk-seeking behavior. To mimic riskseeking behavior at the loss part, we design a narrow margin for the thresholds, which are the value of original thresholds divided by $\lambda$. Note that Lerche and Geldermann [67] also considered the negative flows and threshold setting at the loss part. In this case study, we demonstrate the parameter sets in Table 2 for the DMs and explain their effects to them for ease of selection $[69,71]$. 
TABLE 12: Sensitivity analysis on differentiated decision power of a single DM (university) with conservative group preference.

\begin{tabular}{|c|c|c|c|c|c|c|c|c|c|c|c|c|c|c|c|c|}
\hline \multirow{2}{*}{ Change of decision power } & \multicolumn{15}{|c|}{ Alternatives } & \multirow{2}{*}{ Note } \\
\hline & $A$ & $B$ & C & $D$ & $E$ & $F$ & $G$ & $H$ & $I$ & $J$ & $K$ & $L$ & $M$ & $N$ & $O$ & \\
\hline$-50 \%$ & 2 & 2 & 1 & 14 & 10 & 2 & 15 & 8 & 10 & 2 & 7 & 13 & 6 & 9 & 12 & \\
\hline$-40 \%$ & 2 & 2 & 1 & 14 & 10 & 2 & 15 & 8 & 10 & 2 & 7 & 13 & 6 & 9 & 12 & \\
\hline$-30 \%$ & 2 & 2 & 1 & 14 & 10 & 2 & 15 & 8 & 10 & 2 & 7 & 13 & 6 & 9 & 12 & \\
\hline$-20 \%$ & 4 & 4 & 1 & 14 & 10 & 2 & 15 & 8 & 10 & 2 & 7 & 13 & 6 & 9 & 12 & \\
\hline$-10 \%$ & 4 & 4 & 1 & 14 & 10 & 2 & 15 & 8 & 10 & 2 & 7 & 13 & 6 & 9 & 12 & \\
\hline $0 \%$ & 4 & 4 & 1 & 14 & 10 & 2 & 15 & 8 & 10 & 2 & 7 & 13 & 6 & 9 & 12 & Equal decision power \\
\hline $10 \%$ & 4 & 4 & 1 & 14 & 10 & 2 & 15 & 8 & 10 & 2 & 7 & 13 & 6 & 9 & 12 & \\
\hline $20 \%$ & 4 & 4 & 1 & 14 & 10 & 2 & 15 & 8 & 10 & 2 & 7 & 13 & 6 & 8 & 12 & \\
\hline $30 \%$ & 4 & 4 & 1 & 14 & 10 & 2 & 15 & 8 & 10 & 2 & 7 & 13 & 6 & 8 & 12 & \\
\hline $40 \%$ & 4 & 4 & 1 & 14 & 10 & 2 & 15 & 8 & 10 & 2 & 7 & 13 & 6 & 8 & 12 & \\
\hline $50 \%$ & 4 & 4 & 1 & 14 & 10 & 2 & 15 & 8 & 10 & 2 & 7 & 13 & 6 & 8 & 12 & \\
\hline Rank changes & 1 & 1 & 0 & 0 & 0 & 0 & 0 & 0 & 0 & 0 & 0 & 0 & 0 & 1 & 0 & 3 \\
\hline
\end{tabular}

Note. The total ranks of changes are 3 , whose value is listed in the rightmost cell of the last row.

TABLE 13: Comparison on the total changes of ranks from differentiated decision power.

\begin{tabular}{|c|c|c|c|c|c|c|}
\hline \multirow[b]{2}{*}{ Sensitivity analysis } & \multicolumn{3}{|c|}{ Group preference } & \multicolumn{2}{|c|}{ Without group preference } & \multirow[b]{2}{*}{ Note } \\
\hline & Conservation* & Balance* $^{*}$ & Aggression* & $\begin{array}{l}\text { Macharis } \\
\text { et al. (1998) }\end{array}$ & $\begin{array}{l}\text { S-shaped } \\
\text { function* }\end{array}$ & \\
\hline $\begin{array}{l}\text { Change of decision } \\
\text { power of DM\#1 } \\
\text { (RFMB) }\end{array}$ & 2 & 3 & 4 & 6 & 4 & \\
\hline $\begin{array}{l}\text { Change of decision } \\
\text { power of DM\#2 } \\
\text { (university) }\end{array}$ & 3 & 3 & 2 & 12 & 4 & $\begin{array}{l}\text { Change of weights by } \pm 50 \% \text { of their } \\
\text { original decision power ( } 1 / 3 \text { for each } \\
\text { DM, i.e., equal decision power). }\end{array}$ \\
\hline $\begin{array}{l}\text { Change of decision } \\
\text { power of DM\#3 } \\
\text { (industry) }\end{array}$ & 7 & 7 & 7 & 11 & 7 & \\
\hline
\end{tabular}

Note. (1) Macharis et al. [8] proposed decision weights for differentiated decision power. (2) * Means the use of the S-shaped function from equation (11).

5.2. Weight Assignment. In MCDM problems, weights are commonly used to aggregate the preference of a single criterion for an overall evaluation. The weight generally reflects the importance of a criterion in a DM's mind [76]. PROMETHEE is an additive model combining the preferences of all criteria by their weights, and most of them involve representation in a ratio scale. In searching for a suitable weight set for PROMETHEE, Mareschal [77] proposed weight stability intervals (WSI) on a single criterion for PROMETHEE II and provided the necessary and sufficient conditions. Eppe and De Smet [78] suggested an adaptive query selection scheme for eliciting PROMETHEE II's weight parameters that improved the efficiency of the eliciting phase. Morais et al. [42] utilized rank order centroid (ROC) weights for PROMETHEE-ROC to assess the readiness of technology. De Almeida-Filho et al. [79] provided surrogate weighting procedures for PROMETHEE, while Maghrabiea et al. [80] utilized fuzzy possibility degrees to estimate the weights of PROMETHEE II. These works offer robust inputs to our proposed decision support.

In our case study, one weight set comes from a direct weight assignment and the other two are from a eigenvector method (in AHP). The weight sets denote concerns on different aspects or criteria. The group weight just takes an average of the individual weights for simplicity. Since this
PROMETHEE-based GDSS concentrates on the effects of thresholds, we do not examine the effect of weight changes. This study also does not take into account the consensus or negotiation issue (e.g., Ishizaka and Nemery [43]), due to just a few members in the group. These two issues could be left for further study.

5.3. Consensus Reaching. For the aggregation of individuals' preferences into a group preference, social choice focuses on combining individual opinions, preferences, interests, or welfares to reach a collective decision, but there is no procedure for the aggregation without violating some conditions of Arrow's impossibility theorem [81]. From a practical aspect, the aggregation of a group's preference is still possible if consensus exists in the group, as it is reached through feedback and discussion among group members [82]. Here, the core process is to measure the consensus. Ben-Arieh and Easton [83] organized the approaches on measuring consensus into four categories: (i) counting the number of members who share the group opinion; (ii) measuring distances between the participants; (iii) comparing similarity and differences among group members; and (iv) ordering the alternatives according to the group and its members. Zhang et al. [12] reviewed the feedback 
mechanisms on the process of reaching a consensus. The general framework includes four steps: expressing/modifying individuals' preferences, aggregation function, consensus measure, and preference-modification suggestions. The above works indeed provide fruitful issues in dealing with reaching a consensus.

In the area of group PROMETHEE, there are a few works to cope with consensus. Goletsis et al. [17] proposed the indices of PSI, GSI, RGSI, and AI for checking group consensus so as to aid in further negotiation. Haralambopoulos and Polatidis [37] fostered group consensus through sensitivity and weight interval analyses. Ishizaka and Nemery [43] provided a multiphase approach location selection and partner grouping, in which negotiations are done by interactive communication in their fifth phase. Mahmoudi et al. [84] suggested a hybrid fuzzy-intelligent system for group PROMETHEE II and employed a similarity measure and a threshold value to measure the consensus of the group. De Almeida-Filho et al. [79] proposed quartilebased voting for preventive maintenance management of a water supply system. However, only two quartiles, highestrank alternatives and punished alternatives, are considered for the final group decision. Govindan et al. [46] presented a compromise recommendation from an analysis of pairwise relations in the individuals' ranks. Akram et al. [50] offered a bipolar fuzzy group PROMETHEE in which individuals' ratings are averaged into a group rating without thinking about a consensus. We observe that many interesting consensus reaching techniques can facilitate a compromise or an agreement for group PROMETHEE under the framework of Zhang et al. [12], and these could be left for future study.

5.4. Fuzzy Process. Radojevic and Petrovic [85] proposed a fuzzy approach to the preference structure in PROMETHEE II ranking, taking advantage of three-level linguistic terms as a DM's preference structure, using fuzzy If-Then rules for the operations, and employing a defuzzifier process to obtain the crisp values of alternatives for ranking. Le Téno and Mareschal [2] suggested an interval version of PROMETHEE I with ill-defined data. By introducing basic arithmetic operations on intervals, interval flows can be obtained and compared, and the alternatives are then ranked after a defuzzification operation. Geldermann et al. [86] considered fuzzy data on preferences, scores, and weights in PROMETHEE I/II for an environmental evaluation. After employing the operations of trapezoidal fuzzy numbers, the fuzzy entering and leaving flows are calculated, and aggregated fuzzy judgments are made after a defuzzification process. Goumas and Lygerou [87] extended PROMETHEE II with fuzzy input data for assessing energy exploitation projects. Through the operations of triangular fuzzy numbers on the performances of alternatives on each criterion and criterion weight, the net flows of each alternative can be acquired. Utilizing the Yager index, the crisp values of net flows of alternatives are derived and compared. Different from processing fuzzy data in a previous work, FernándezCastro and Jiménez [88] used PROMETHEE III and fuzzy integer linear programming to improve traditional PROMETHEE IV, noting that a more realistic model can be produced, because many constraints should be treated as soft in the real world.

Zhang et al. [89] compared PROMETHEE II and fuzzy PROMETHEE II for ranking contaminated sites. Because some environmental indices or criteria have a range of values, selecting their highest values always exaggerates the risk level in a decision and thus promotes the fuzzy approach with a defuzzification process. $\mathrm{Li}$ and $\mathrm{Li}$ [90] considered linguistic variables on criteria weights and alternatives' ratings on each criterion for PROMETHEE II. Liao and Xu [91] proposed an intuitionistic fuzzy PROMETHEE to make decisions for depicting more preference information. Celika and Gumus [92] suggested a hybrid approach, consisting of interval type-2 fuzzy AHP and PROMETHEE, to evaluate the emergency preparedness and response ability performances of nongovernmental humanitarian relief organizations. Vavatsikos et al. [13] integrated fuzzy PROMETHEE II into geographical information system-based suitability analysis for location rankings.

After reviewing some representative developments of fuzzy PROMETHEE, we find that fuzzy approaches involve inaccurate measurement or linguistic terms from the input of PROMETHEE, which is categorized as the third uncertain source by Roy [14] and acts in a similar role as PROMETHEE III. It would be interesting to discuss the choice between fuzzy PROMETHEE I/II and PROMETHEE III. In addition to the debates between fuzzy and crisp sets [19, 23], one faces the disadvantages of information distortion and cumbersome calculation in fuzzy approaches. Therefore, PROMETHEE III could be a better option to get rid of such disadvantages. On the other hand, the process on linguistic input terms can be handled through a preprocess proposed by Shih [23], or one can directly employ Types I, II, or IV function, so that PROMETHEE III is able to do the evaluation.

5.5. Complexity Analysis. To compare different algorithms, it is interesting to find the most efficient one for solving a problem [93]. In the area of computer science, the computational complexity or simply complexity of an algorithm is the amount of resources (i.e., time and memory/storage requirements) required to run it. The issue began around 1960 after digital computers began to solve the problems in which the experts tried to know if the problems were solvable under resource constraints [94]. The consumed time of an algorithm later was considered as a benchmark for efficiency evaluation of an algorithm. For instance, the Karmarkar algorithm for linear programming is proven to be polynomial-time, which is a reasonably efficient algorithm [95].

In the area of MCDM, multiobjective optimization problems have the same core of mathematical programming, and some developments involve complexity analysis, especially for proposing a new algorithm or comparing different algorithms [96]. On the other side, there are a few works considering complexity analysis in multiattribute decision 


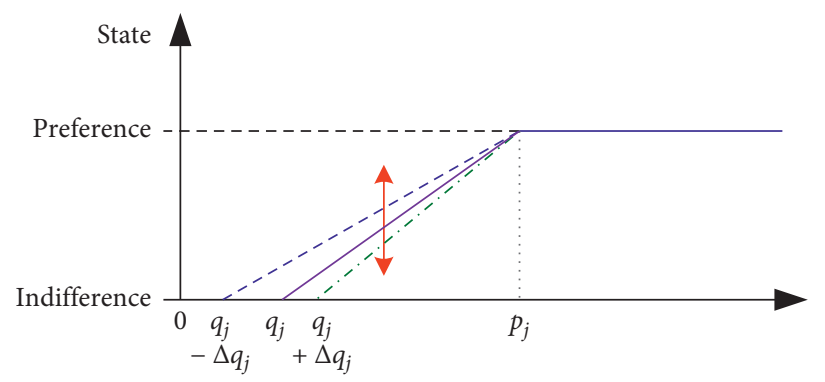

(a)

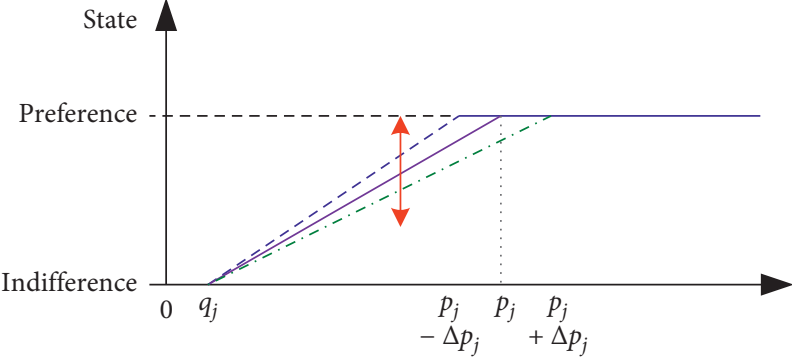

(b)

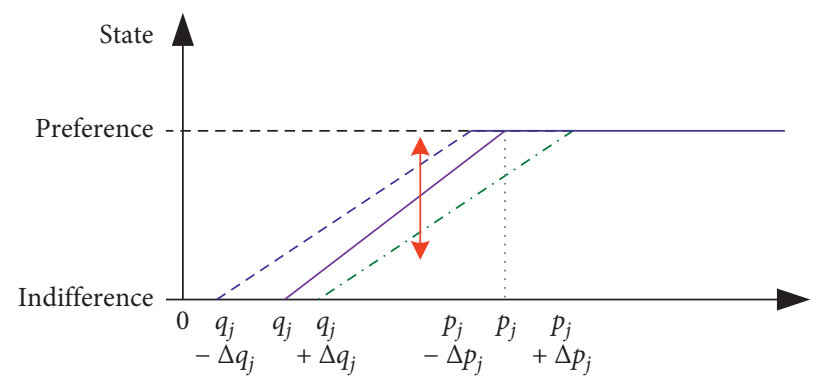

(c)

FIGURE 4: Preference changes of the DM on the changes in the thresholds on criterion $j, j=1, \ldots, n$. (a) Change of DM's preference on the change in the indifference threshold. (b) Change of DM's preference on the change in the preference threshold. (c) Change of DM's preference on the change in both thresholds in the same direction.

making or discrete MCDM due to its simplicity representation in a discrete domain with finite numbers of alternatives and criteria. To the best of our knowledge, some sorting and/ or hybrid algorithms by MADM have discussed the contents of complexity analysis [97, 98], due to the fact that these operations are more complex than arithmetic operations. In general, the core of PROMETHEE makes use of arithmetic operations for the calculation, and there is no problem on computational complexity. PROMETHEE III adds a process of checking their indifference relations, and it empirically incurs no stated problem.

Our proposed model extends PROMETHEE III by two parts. The first one involves threshold manipulation, which is outside the process of PROMETHEE and has no effect on the computation. The second one engages the calculation of the S-shaped function with power functions. Though it also empirically incurs no stated problem, we have built the problem size to 60 alternatives and found the proposed model does not exhibit computational difficulties. This fact shows that the proposed model is affordable for computation via Excel on medium-size problems.

\section{Conclusions}

This study has proposed a threshold-enhanced PROMETHEE group decision support under uncertainties, suggesting that a comprehensive structure of group decision support can cover a variety of individual and group decision information. The analytic results of the illustrative example show that the decision support has an edge in better rank invariance under an uncertain environment and that rank differences from group decisions with different group preferences do converge. Sensitivity analyses allow us to see the details of the group PROMETHEE, in which the conservative group preference generates more diverse rankings than the other two preferences. Hence, we need to exploit its thresholds with caution. Other analyses on differentiated decision power illustrate that the proposed approach is more stable than traditional group PROMETHEE and that S-shaped preference functions yield rank invariance under any situation in the given example.

Appendix A examines the effects from changes in thresholds on a DM's preferences. Six properties have addressed the positive or negative outcomes according to a decrease or increase in the threshold values. Moreover, our proposed threshold enhances group decision support, concentrating upon the demonstration of the effects of thresholds with narrow margins. Thus, weight determination is overall simple and straightforward. Because the weights do have an impact on the final result, we shall leave this for a future study.

The suggested group decision support is coherent with the traditional group PROMETHEE process and is also applicable to PROMETHEE I and II. In addition, the S-shaped function offers the same possibility as well. As we do not consider a probability weight function herein, this can be an important issue for research extension.

In this study we have assumed that consensus in the group has been reached or after a negotiation. Thus, there is no outlier in the group under any group decision. Consensus and negotiation are important issues in group decision and are worth being investigated. Other fuzzy operators, like Hamacher power aggregation operators [99], can also be extensions of this study and be left for future study. 


\section{Appendix}

\section{A. Effects of Changes of Thresholds on the Preference for an Alternative}

This appendix provides some characteristics of the effects from changes of thresholds on the preference for an alternative based on Lin's development [100]. Assume the performances $g_{j}\left(a_{i}\right)$ and $g_{j}\left(a_{i}\right), i$ and $i=1, \ldots, m$, are two alternatives $a_{i}$ and $a_{i}$ evaluated on criterion $j, j=1, \ldots, n$, respectively. The gap between the two performances is $d_{j}=g_{j}\left(a_{i}\right)-g_{j}\left(a_{i}\right)$ on criterion $j$, where $p_{j}$ and $q_{j}$ are the preference and indifference thresholds, respectively, and $q_{j} \leq p_{j}$. We neglect the use of superscripts in notations for the different members of the group without loss of generality. Since Type V function is more general, we utilize it as a representative function. As $d_{j}$ increases, $q_{j} \leq d_{j} \leq p_{j}$, the DM prefers alternatives $a_{i}$ to $a_{i}$, with preference function $P_{j}\left(d_{j}\right)$ moving progressively from indifference to strong preference on the slope $d_{j}-q_{j} / p_{j}-q_{j}$ on criterion $j$. To observe the effects from changes of thresholds on the change of the preference $\Delta P_{j}\left(d_{j}\right)$ for an alternative, we illustrate cases for either one change or both changes of indifference and preference thresholds. Below are some properties with a formulation derivation or numerical data illustration.

Property A.1. For a linear case of Type V linear function, if the change of the indifference threshold $\Delta q_{j}$ increases, then the change of DM's preference $\Delta P_{j}\left(d_{j}\right)$ decreases, whereas a decrease in $\Delta q_{j}$ will cause DM's preference $\Delta P_{j}\left(d_{j}\right)$ to increase [100].

In the interval $q_{j} \leq d_{j} \leq p_{j}$, we set $\Delta q_{j}$ as a small change of the indifference threshold and see its effect on the DM's preference for an alternative. We define $P_{j}^{\prime \prime}\left(d_{j}\right)$ as a preference function under a change of the indifference threshold. The preference difference $\Delta P_{j}\left(d_{j}\right)$ is

$$
\begin{aligned}
\Delta P_{j}\left(d_{j}\right) & =P_{j}^{\prime \prime}\left(d_{j}\right)-P_{j}\left(d_{j}\right), \\
& =\frac{d_{j}-\left(q_{j}+\Delta q_{j}\right)}{p_{j}-\left(q_{j}+\Delta q_{j}\right)}-\frac{d_{j}-q_{j}}{p_{j}-q_{j}}, \\
& =\frac{-\left(p_{j}-d_{j}\right) \Delta q_{j}}{\left(p_{j}-q_{j}\right)\left[p_{j}-\left(q_{j}+\Delta q_{j}\right)\right]} .
\end{aligned}
$$

As $q_{j} \leq d_{j} \leq p_{j}$, we know that $p_{j}-q_{j}>0$ and $p_{j}-\left(q_{j}+\Delta q_{j}\right)$ $>0$ with a small change of $\Delta q_{j}$. Hence, the denominator of equation (A.3) is positive. The effect mainly depends on the sign and value of the nominator of equation (A.3). When the change of the indifference threshold $\Delta q_{j}$ increases, the change of DM's preference $\Delta P_{j}\left(d_{j}\right)$ decreases. Conversely, if $\Delta q_{j}$ decreases, then $\Delta P_{j}\left(d_{j}\right)$ increases.

Property A.2. For Type V linear function, if a change of the preference threshold $\Delta p_{j}$ increases, then the change of DM's preference $\Delta P_{j}\left(d_{j}\right)$ decreases, whereas a decrease in $\Delta p_{j}$ will cause DM's preference $\Delta P_{j}\left(d_{j}\right)$ to increase [100].
We set $\Delta p_{j}$ as a small change of the preference threshold to see its effect on the preference for an alternative:

$$
\begin{aligned}
\Delta P_{j}\left(d_{j}\right) & =\frac{d_{j}-q_{j}}{\left(p_{j}+\Delta p_{j}\right)-q_{j}}-\frac{d_{j}-q_{j}}{p_{j}-q_{j}}, \\
& =\frac{-\left(d_{j}-q_{j}\right) \Delta p_{j}}{\left(p_{j}-q_{j}\right)\left[\left(p_{j}+\Delta p_{j}\right)-q_{j}\right]} .
\end{aligned}
$$

The denominator of equation (A.5) is positive for $q_{j} \leq d_{j} \leq p_{j}$ with a small change of $\Delta p_{j}$. When the change of the preference threshold $\Delta p_{j}$ increases, the change of preference $\mathrm{DM} \Delta P_{j}\left(d_{j}\right)$ decreases. Conversely, if $\Delta p_{j}$ decreases, then $\Delta P_{j}\left(d_{j}\right)$ increases.

Property A.3. For Type V function, if changes of the indifference and preference thresholds increase or decrease simultaneously, then the change of DM's preference decreases, whereas a decrease in both thresholds will cause DM's preference to increase.

To describe the two thresholds simultaneously, we take the formula of equation (A.1) and obtain the following expression:

$$
\begin{aligned}
\Delta P_{j}\left(d_{j}\right) & =\frac{d_{j}-\left(q_{j}+\Delta q_{j}\right)}{\left(p_{j}+\Delta p_{j}\right)-\left(q_{j}+\Delta q_{j}\right)}-\frac{d_{j}-q_{j}}{p_{j}-q_{j}} \\
& =\frac{-\left(p_{j}-d_{j}\right) q_{j}-\left(d_{j}-q_{j}\right) \Delta p_{j}}{\left[\left(p_{j}+\Delta p_{j}\right)-\left(q_{j}+\Delta q_{j}\right)\right]\left(p_{j}-q_{j}\right)} .
\end{aligned}
$$

Since $q_{j} \leq d_{j} \leq p_{j}$, we know that the denominator of equation (A.7) is positive with small changes of $\Delta q_{j}$ and $\Delta p_{j}$. When changes of the indifference and preference thresholds, $\Delta q_{j}$ and $\Delta p_{j}$, increase simultaneously, the change of preference $\Delta P_{j}\left(d_{j}\right)$ also decreases. In the opposite direction, if $\Delta q_{j}$ and $\Delta p_{j}$ decrease, then $\Delta P_{j}\left(d_{j}\right)$ increases.

Figure 4 illustrates the three properties on the change of thresholds. Subfigures (a), (b), and (c) demonstrate the variation of DM's preference on a change of the indifference and preference thresholds, as well as a change of both thresholds in the same direction, respectively. The red line with arrows on both sides shows the changes of DM's preference. We easily see how the DM's preference strengthens or weakens as the arrow moves up or down. The figure also illustrates that a sharp slope could enhance DM's preference.

Note that $\Delta q_{j}$ and $\Delta p_{j}$ rise or fall in opposite directions. Under the situation of $\Delta q_{j}$ and $\Delta p_{j}$ having one positive number and one negative number, the effect on the change of preference $\Delta P_{j}\left(d_{j}\right)$ should be less. From the nominator of equation (A.7), the actual change of preference $\Delta P_{j}\left(d_{j}\right)$ relies on the relative values of $d_{j}, \Delta q_{j}$, and $\Delta p_{j}$.

We further investigate the terms in the denominator of equation (A.7) and define it as

$$
D=\left[\left(p_{j}+\Delta p_{j}\right)-\left(q_{j}+\Delta q_{j}\right)\right]\left(p_{j}-q_{j}\right) .
$$

If $\Delta p_{j}$ decreases and $\Delta q_{j}$ increases, then the values of $\left[\left(p_{j}+\Delta p_{j}\right)-\left(q_{j}+\Delta q_{j}\right)\right]$ in denominator $D$ decrease and 
thus cause DM's preference $\Delta P_{j}\left(d_{j}\right)$ to increase. For the movement in opposite directions, if $\Delta p_{j}$ increases and $\Delta q_{j}$ decreases, then the values of denominator $D$ increase and thus result in DM's preference to decrease. In the first case, the movement of $\Delta p_{j}$ and $\Delta q_{j}$ generates a steep slope as Figure $1(\mathrm{~d})$ shows. In the second case, $\Delta p_{j}$ and $\Delta q_{j}$ move in opposite directions simultaneously, forming a gradual slope as in Figure 1(b).

When considering S-shaped function of equation (11), there is a two-part nonlinear function for gain and loss, depending on the value of $d_{j}$. We follow the same style and illustrate the effects on the DM's preference in their original forms due to less chance of reducing them to simple forms.

Property A.4. For a nonlinear case of S-shaped preference function, if a change of indifference threshold $\Delta q_{j}$ increases, then the change of preference $\Delta P_{j}\left(d_{j}\right)$ decreases, whereas a decrease in $\Delta p_{j}$ causes $\Delta P_{j}\left(d_{j}\right)$ to increase

Following the similar fashion of Property A.1, the following two equations denote the change of preference $\Delta P_{j}\left(d_{j}\right)$ with a change of indifference threshold for a gain and loss, respectively:

$$
\begin{aligned}
\Delta P_{j}\left(d_{j}\right)= & {\left[\frac{d_{j}-\left(q_{j}+\Delta q_{j}\right)}{p_{j}-\left(q_{j}+\Delta q_{j}\right)}\right]^{\alpha} } \\
& -\left[\frac{d_{j}-q_{j}}{p_{j}-q_{j}}\right]^{\alpha}, \quad \text { for gain, } \\
\Delta P_{j}\left(d_{j}\right)= & {\left[\frac{-d_{j}+\left(q_{j}+\Delta q_{j} / l\right)}{\left(-p_{j}+q_{j}+\Delta q_{j}\right) / l}\right]^{\beta} } \\
& +\left[\frac{-d_{j}+\left(q_{j} / l\right)}{\left(-p_{j}+q_{j}\right) / l}\right]^{\beta}, \text { for loss. }
\end{aligned}
$$

We illustrate the property through Example A.1 with the given data.

Property A.5. For S-shaped two-part nonlinear preference function, if the change of preference threshold $\Delta p_{j}$ increases, then the change of preference $\Delta P_{j}\left(d_{j}\right)$ decreases, whereas a decrease in $\Delta p_{j}$ causes DM's preference $\Delta P_{j}\left(d_{j}\right)$ to increase.

The following two equations show the change of preference $\Delta P_{j}\left(d_{j}\right)$ with a change of the preference threshold for a gain and loss, respectively:

$$
\begin{aligned}
\Delta P_{j}\left(d_{j}\right)= & {\left[\frac{d_{j}-q_{j}}{\left(p_{j}+\Delta p_{j}\right)-q_{j}}\right]^{\alpha} } \\
& -\left[\frac{d_{j}-q_{j}}{p_{j}-q_{j}}\right]^{\alpha}, \text { for gain, } \\
\Delta P_{j}\left(d_{j}\right)= & {\left[\frac{-d_{j}+\left(q_{j} / l\right)}{\left(-p_{j}+q_{j}-\Delta p_{j}\right) / l}\right]^{\beta} } \\
& +\left[\frac{-d_{j}+\left(q_{j} / l\right)}{\left(-p_{j}+q_{j}\right) / l}\right]^{\beta}, \text { for loss. }
\end{aligned}
$$

\section{B. Case Description}

Taiwan created the Recycling Fund Management Board

(RFMB) under the Environmental Protection Administration

We demonstrate the property through the example.

Property A.6. For S-shaped nonlinear function, if changes of indifference and preference thresholds increase/decrease simultaneously, then the change of DM's preference decreases, whereas a decrease in both thresholds cause DM's preference to increase.

The next two equations present the change of preference $\Delta P_{j}\left(d_{j}\right)$ with a change of the indifference threshold for a gain and loss, respectively:

$$
\begin{aligned}
\Delta P_{j}\left(d_{j}\right)= & {\left[\frac{d_{j}-\left(q_{j}+\Delta q_{j}\right)}{\left(p_{j}+\Delta p_{j}\right)-\left(q_{j}+\Delta q_{j}\right)}\right]^{\alpha} } \\
& -\left[\frac{d_{j}-q_{j}}{p_{j}-q_{j}}\right]^{\alpha}, \text { for gain, } \\
\Delta P_{j}\left(d_{j}\right)= & {\left[\frac{-d_{j}+\left(q_{j}+\Delta q_{j} / l\right)}{\left(-p_{j}+\Delta p_{j}+q_{j}+\Delta q_{j}\right) / l}\right]^{\beta} } \\
& +\left[\frac{-d_{j}+\left(q_{j} / l\right)}{\left(-p_{j}+q_{j}\right) / l}\right]^{\beta}, \text { for loss. }
\end{aligned}
$$
follows.

We describe the property through Example A.1 as

Example A.1. Comparing the effects from changes of indifference and preference thresholds

The main data from our case, $q_{j}=0.15$ and $p_{j}=0.35$, come from the first criterion of the expert of RFMB (Table 4). We take their average, $d_{j}=0.25$, for a better illustration and set small numbers $\Delta p_{j}= \pm 0.02$ and $\Delta q_{j}= \pm 0.01$ for either increase or decrease, respectively. Equations (A.3), (A.5), and (A.7) are for counting the change of the preference $\Delta \mathrm{Pj}(\mathrm{dj})$ for Type $\mathrm{V}$ function. We take the gain and loss parts of equations (A.9)-(A.14) with $\alpha=0.725, \beta=0.717$, and $\lambda=2.04$ and other suggestions for the comparison. Table 4 lists the comparison of the DM's preference changes. The results show that Properties A.1, A.2, A.4, and A.5 hold in the upper part of the table. Based on the given data, the change of preference $\Delta P_{j}\left(d_{j}\right)$ is less influenced by a small change of thresholds when using S-shaped function versus using Type $\mathrm{V}$ function, and the loss function is the least affected one. All DM's preference changes are greater than the changes of thresholds.

The effects of small changes on both thresholds show a common interest. We thus exploit the combinations of the above data of $\Delta p_{j}$ and $\Delta q_{j}$ and list the four cases in the lower part of Table 4. The results indicate that Properties A.3 and A.6 hold. The last four rows of Table 4 provide opposite phenomena for when small changes of the indifference and preference thresholds move in opposite directions. 
in 1998 to encourage waste recycling and thus reduce damage to the environment. RFMB collects funds from manufacturers and monitors waste materials flow by granting subsidies to the recycling industry. Since hazardous materials are a major concern, RFMB has pushed users to recycle their waste electronics items since 2001. After a decade of policy implementation through a flat subsidy rate, some basic RFMB goals have been achieved, but there is further opportunity to promote the recycling capability and competitiveness of WEEE treatment plants. RFMB set up a project to score 15 WEEE treatment plants and to rank and classify them based upon their performance indices. RFMB offers an extra subsidy rate if a plant's performance is above the standard and gives lower rates if performance is fair or not good. RFMB also forces those plants performing under the standard to improve their recycling capability [20]. RFMB is looking for a new evaluation technology.

RFMB first established feasible indicators based on the concept of Electronic Product Environmental Assessment Tool under the guidance of the ISO 14030 Standard. There are 43 indicators grouped into 5 aspects: environment protection, management system, financial performance, technology achievement, and social responsibility:

(i) Environment protection is for regulatory compliance, waste process examination, and contaminant collection

(ii) Management system is for operations quality, plant worker and environment, and international certifications of OHSAS 180001, ISO 14064, and EN 16001/ISO 50001

(iii) Financial performance is for financial information disclosure, operations efficiency, the ability to repay debt, profitability, and company size

(iv) Technology achievement is for waste processing specifications compliance, advanced resource recycling potentials, and reverse logistics chain integration

(v) Social responsibility is for corporate social responsibility, establishment of recycling depots, and efforts put forth on corporate social image

Table 5 lists the performance data of these 15 plants by aspect.

\section{Data Availability}

For more information on the calculation of the demonstrated example, please visit: https:/drive.google.com/drive/ folders/16otvW6AnwBNNhH73uXzuC5QFl4WI8SeH? $\mathrm{usp}=$ sharing.

\section{Conflicts of Interest}

The author declares no conflicts of interest regarding the publication of this study.

\section{Acknowledgments}

The author is grateful to Professor Tzong-Ru Tsai at Tamkang University, Professor David L. Olson at University of
Nebraska-Lincoln, and Professor Ue-Pyng Wen and Dr. Che-Wei Tsui at National Tsing Hua University, Taiwan, for their valuable help. Funding behind this paper was supported by the Ministry of Science and Technology, Taiwan, R.O.C. under the grant number MOST 102-2221-E-032-025MY2.

\section{References}

[1] J. P. Brans and P. Vincke, "Note-A preference ranking organisation method," Management Science, vol. 31, no. 6, pp. 647-656, 1985.

[2] J. F. Le Téno and B. Mareschal, "An interval version of PROMETHEE for the comparison of building products' design with ill-defined data on environmental quality," European Journal of Operational Research, vol. 109, no. 2, pp. 522-529, 1998.

[3] J.-P. Brans and Y. De Smet, "PROMETHEE methods," in Multiple Criteria Decision Analysis, J. Figueira, S. Greco, and M. Ehrgott, Eds., Springer, New York, NY, USA, pp. 187219, 2016.

[4] B. Mareschal, PROMETHEE Bibliographical Statistics, 2020.

[5] A. Tversky and D. Kahneman, "Advances in prospect theory: cumulative representation of uncertainty," Journal of Risk and Uncertainty, vol. 5, no. 4, pp. 297-323, 1992.

[6] C.-L. Hwang and M.-J. Lin, Group Decision Making, Springer, Berlin, Germany, 1987.

[7] M. Baucells and R. K. Sarin, "Group decisions with multiple criteria," Management Science, vol. 49, pp. 1105-1118, 2003.

[8] C. Macharis, J. P. Brans, and B. Mareschal, "The GDSS PROMETHEE procedure - a PROMETHEE-GAIA based procedure for group decision support," Journal of Decision Systems, vol. 7, pp. 283-307, 1998.

[9] C.-W. Tsui, G.-H. Tzeng, and U.-P. Wen, "A hybrid MCDM approach for improving the performance of green suppliers in the TFT-LCD industry," International Journal of Production Research, vol. 53, no. 21, pp. 6436-6454, 2015.

[10] C. Macharis, B. Mareschal, J. P. Waaub, and L. Milan, "PROMETHEE-GDSS revisited: applications so far and new developments," International Journal of Multicriteria Decision Making, vol. 5, no. 1/2, pp. 129-151, 2015.

[11] Y. He and $\mathrm{Z}$. Xu, "A consensus framework with different preference ordering structures and its applications in human resource selection," Computers \& Industrial Engineering, vol. 118, pp. 80-88, 2018.

[12] H. Zhang, S. Zhao, G. Kou, C.-C. Li, Y. Dong, and F. Herrera, "An overview on feedback mechanisms with minimum adjustment or cost in consensus reaching in group decision making: research paradigms and challenges," Information Fusion, vol. 60, pp. 65-79, 2020.

[13] A. P. Vavatsikos, O. E. Demesouka, and K. P. Anagnostopoulos, "GIS-based suitability analysis using fuzzy PROMETHEE," Journal of Environmental Planning and Management, vol. 63, no. 4, pp. 604-628, 2020.

[14] B. Roy, "Main sources of inaccurate determination, uncertainty and imprecision in decision models," Mathematical and Computer Modelling, vol. 12, no. 10-11, pp. 1245-1254, 1989.

[15] E. Herrera-Viedma, F. Herrera, and F. Chiclana, "A consensus model for multiperson decision making with different preference structures," IEEE Transactions on Systems, Man, and Cybernetics - Part A: Systems and Humans, vol. 32, no. 3, pp. 394-402, 2002. 
[16] B. Zhang, Y. Dong, and E. Herrera-Viedma, "Group decision making with heterogeneous preference structures: an automatic mechanism to support consensus reaching," Group Decision and Negotiation, vol. 28, no. 3, pp. 585-617, 2019.

[17] Y. Goletsis, J. Psarras, and J. Samouilidis, "Project ranking in the Armenian energy sector using a multicriteria method for groups," Annals of Operations Research, vol. 120, no. 1/4, pp. 135-157, 2003.

[18] L. Dias and J. Clímaco, "ELECTRE TRI for groups with imprecise information on parameter values," Group Decision and Negotiation, vol. 9, no. 5, pp. 355-377, 2000.

[19] H.-S. Shih, H.-J. Shyur, and E. S. Lee, "An extension of TOPSIS for group decision making," Mathematical and Computer Modelling, vol. 45, no. 7-8, pp. 801-813, 2007.

[20] H.-S. Shih, "Incremental analysis for MCDM with an application to group TOPSIS," European Journal of Operational Research, vol. 186, no. 2, pp. 720-734, 2008.

[21] E. Forman and K. Peniwati, "Aggregating individual judgments and priorities with the analytic hierarchy process," European Journal of Operational Research, vol. 108, no. 1, pp. 165-169, 1998.

[22] C. Parkan and M.-L. Wu, "Process selection with multiple objective and subjective attributes," Production Planning \& Control, vol. 9, no. 2, pp. 189-200, 1998.

[23] H.-S. Shih, "A mixed-data evaluation in group TOPSIS with differentiated decision power," Group Decision and Negotiation, vol. 25, no. 3, pp. 537-565, 2016.

[24] H.-S. Shih, C.-H. Wang, and E. S. Lee, "A multiattribute GDSS for aiding problem-solving," Mathematical and Computer Modelling, vol. 39, no. 11-12, pp. 1397-1412, 2004.

[25] G. Colson, "The OR's prize winner and the software ARGOS: how a multijudge and multicriteria ranking GDSS helps a jury to attribute a scientific award," Computers \& Operations Research, vol. 27, no. 7-8, pp. 741-755, 2000.

[26] B. Mareschal, Preference Functions and Thresholds, 2018.

[27] B. Roy, M. Présent, and D. Silhol, "A programming method for determining which Paris metro stations should be renovated," European Journal of Operational Research, vol. 24, no. 2, pp. 318-334, 1986.

[28] B. Roy, J. R. Figueira, and J. Almeida-Dias, "Discriminating thresholds as a tool to cope with imperfect knowledge in multiple criteria decision aiding: theoretical results and practical issues," Omega, vol. 43, pp. 9-20, 2014.

[29] M. Rogers and M. Bruen, "Choosing realistic values of indifference, preference and veto thresholds for use with environmental criteria within ELECTRE," European Journal of Operational Research, vol. 107, no. 3, pp. 542-551, 1998.

[30] V. Cantillo, J. Amaya, and J. d. D. Ortúzar, "Thresholds and indifference in stated choice Surveys," Transportation Research Part B: Methodological, vol. 44, no. 6, pp. 753-763, 2010.

[31] C. Achillas, C. Vlachokostas, N. Moussiopoulos, and G. Banias, "Decision support system for the optimal location of electrical and electronic waste treatment plants: a case study in Greece," Waste Management, vol. 30, no. 5, pp. 870-879, 2010.

[32] H. Frikha, H. Chabchoub, and J. M. Martel, "An interactive disaggregation approach inferring the indifference and the preference thresholds of PROMETHEE II," International Journal of Multicriteria Decision Making, vol. 1, no. 4, pp. 365-393, 2011.

[33] I. Banamar and Y. De Smet, An Extension of PROMETHEE II to Temporal Evaluations, Université Libre de Bruxelles, City of Brussels, Belgium, 2016.
[34] B. Kourmpanis, A. Papadopoulos, K. Moustakas, F. Kourmoussis, M. Stylianou, and M. Loizidou, "An integrated approach for the management of demolition waste in Cyprus," Waste Management \& Research: The Journal for a Sustainable Circular Economy, vol. 26, no. 6, pp. 573-581, 2008.

[35] M. E. Demircioğlu and H. Z. Ulukan, "A novel hybrid approach based on intuitionistic fuzzy multi criteria groupdecision making for environmental pollution problem," Journal of Intelligent and Fuzzy Systems, vol. 38, pp. 1013$1025,2020$.

[36] E. Georgopoulou, Y. Sarafidis, and D. Diakoulaki, "Design and implementation of a group DSS for sustaining renewable energies exploitation," European Journal of Operational Research, vol. 109, no. 2, pp. 483-500, 1998.

[37] D. A. Haralambopoulos and H. Polatidis, "Renewable energy projects: structuring a multi-criteria group decision-making framework," Renewable Energy, vol. 28, no. 6, pp. 961-973, 2003.

[38] D. C. Morais and A. T. De Almeida, "Group decision-making for leakage management strategy of water network," Resources, Conservation and Recycling, vol. 52, no. 2, pp. 441459, 2007.

[39] V. B. S. Silva, D. C. Morais, and A. T. Almeida, "A multicriteria group decision model to support watershed committees in Brazil," Water Resources Management, vol. 24, no. 14, pp. 4075-4091, 2010.

[40] A. Roozbahani, B. Zahraie, and M. Tabesh, "PROMETHEE with precedence order in the criteria (PPOC) as a new group decision making aid: an application in urban water supply management," Water Resources Management, vol. 26, no. 12, pp. 3581-3599, 2012.

[41] D. S. Yakowitz, L. J. Lane, and F. Szidarovszky, "Multi-attribute decision making: dominance with respect to an importance order of the attributes," Applied Mathematics and Computation, vol. 54, no. 2-3, pp. 167-181, 1993.

[42] D. C. Morais, A. T. De Almeida, L. H. Alencar, T. R. N. Clemente, and C. Z. B. Cavalcanti, "PROMETHEEROC model for assessing the readiness of technology for generating energy," Mathematical Problems in Engineering, vol. 2015, Article ID 530615, 11 pages, 2015.

[43] A. Ishizaka and P. Nemery, "A multi-criteria group decision framework for partner grouping when sharing facilities," Group Decision and Negotiation, vol. 22, no. 4, pp. 773-799, 2013.

[44] M. Behzadian, S.-M. Hosseini-Motlagh, J. Ignatius, M. Goh, and M. M. Sepehri, "PROMETHEE group decision support system and the house of quality," Group Decision and Negotiation, vol. 22, no. 2, pp. 189-205, 2013.

[45] M. Tavana, M. Behzadian, M. Pirdashti, and H. Pirdashti, "A PROMETHEE-GDSS for oil and gas pipeline planning in the Caspian Sea basin," Energy Economics, vol. 36, pp. 716-728, 2013.

[46] K. Govindan, M. Kadziński, and R. Sivakumar, "Application of a novel PROMETHEE-based method for construction of a group compromise ranking to prioritization of green suppliers in food supply chain," Omega, vol. 71, pp. 129-145, 2017.

[47] Ž. Živković, D. Nikolić, M. Savić, P. Djordjević, and I. Mihajlović, "Prioritizing strategic goals in higher education organizations by using a SWOT-PROMETHEE/ GAIA-GDSS model," Group Decision and Negotiation, vol. 26, pp. 829-846, 2017. 
[48] M. Abdelhadi, D. Hamdadou, and N. Menni, "A communication platform for group decision support system," International Journal of E-Services and Mobile Applications, vol. 10, no. 3, pp. 19-41, 2018.

[49] L. Zhang, J. Zhan, Z. Xu, and J. C. R. Alcantud, "Coveringbased general multigranulation intuitionistic fuzzy rough sets and corresponding applications to multi-attribute group decision-making," Information Sciences, vol. 494, pp. 114140, 2019.

[50] M. Akram, Shumaiza, and A. N. Al-Kenani, "Multi-criteria group decision-making for selection of green suppliers under bipolar fuzzy PROMETHEE process," Symmetry, vol. 12, no. 1, p. 77, 2020.

[51] M. Soba, Y. Ersoy, A. T. Altınay, B. Erkan, and E. Şik, "Application of multiple criteria decision-making methods in assignment place selection," Mathematical Problems in Engineering, vol. 2020, Article ID 6748342, 13 pages, 2020.

[52] D. C. Morais and A. T. De Almeida, "Group decision making on water resources based on analysis of individual rankings," Omega, vol. 40, no. 1, pp. 42-52, 2012.

[53] J. P. Brans, P. Vincke, and B. Mareschal, "PROMETHEE: a new family of outranking methods in multicriteria analysis," in Operations Research '84, J. P. Brans, Ed., pp. 477-491, North-Holland, New York, NY, USA, 1984.

[54] G.-H. Tzeng and J.-J. Huang, Multiple Attribute Decision Making, CRC Press, Boca Raton, FL, USA, 2011.

[55] H.-S. Shih, Y.-T. Chang, and C.-P. Cheng, "A generalized PROMETHEE III with risk preferences on losses and gains," International Journal of Information and Management Sciences, vol. 27, pp. 117-127, 2016.

[56] S. Greco, A. Ishizaka, M. Tasiou, and G. Torrisi, "The ordinal input for cardinal output approach of non-compensatory composite indicators: the PROMETHEE scoring method," European Journal of Operational Research, vol. 288, no. 1, pp. 225-246, 2021.

[57] M. Abdellaoui, H. Bleichrodt, and C. Paraschiv, "Loss aversion under prospect theory: a parameter-free measurement," Management Science, vol. 53, no. 10, pp. 1659-1674, 2007.

[58] H. Xu, J. Zhou, and W. Xu, "A decision-making rule for modeling travelers' route choice behavior based on cumulative prospect theory," Transportation Research Part C: Emerging Technologies, vol. 19, no. 2, pp. 218-228, 2011.

[59] S. Ebert and D. Wiesen, "Joint measurement of risk aversion, prudence, and temperance," Journal of Risk and Uncertainty, vol. 48, no. 3, pp. 231-252, 2014.

[60] A. E. Attema, W. B. F. Brouwer, O. l'Haridon, and J. L. Pinto, "An elicitation of utility for quality of life under prospect theory," Journal of Health Economics, vol. 48, pp. 121-134, 2016.

[61] O. Krčál, M. Kvasnička, and R. Staněk, "External validity of prospect theory: the evidence from soccer betting," Journal of Behavioral and Experimental Economics, vol. 65, pp. 121-127, 2016.

[62] G. Heutel, "Prospect theory and energy efficiency," Journal of Environmental Economics and Management, vol. 96, pp. 236-254, 2019.

[63] P. Korhonen, H. Moskowitz, and J. Wallenius, "Choice behavior in interactive multiple-criteria decision making," Annals of Operations Research, vol. 23, no. 1, pp. 161-179, 1990.

[64] P. Salminen and J. Wallenius, "Testing prospect theory in a deterministic multiple criteria decision-making environment," Decision Sciences, vol. 24, no. 2, pp. 279-294, 1993.
[65] P. Salminen, "Solving the discrete multiple criteria problem using linear prospect theory," European Journal of Operational Research, vol. 72, no. 1, pp. 146-154, 1994.

[66] P. J. Korhonen, J. Wallenius, T. Genc, and P. Xu, "On rational behavior in multi-attribute riskless choice," European Journal of Operational Research, 2020.

[67] N. Lerche and J. Geldermann, "Integration of prospect theory into PROMETHEE - a case study concerning sustainable bioenergy concepts," International Journal of Multicriteria Decision Making, vol. 5, no. 4, pp. 309-333, 2015.

[68] L. F. A. M. Gomes and M. M. P. P. Lima, "TODIM: basics and application to multi-criteria ranking of projects with environmental impacts," Foundations of Computing and Decision Sciences, vol. 16, pp. 113-127, 1991.

[69] L. F. A. M. Gomes and M. M. P. P. Lima, "From modelling individual preferences to multi-criteria ranking of discrete alternatives: a look at prospect theory and the additive difference model," Foundations of Computing and Decision Sciences, vol. 17, pp. 171-184, 1992.

[70] L. C. Dias and J. N. Climaco, "Dealing with imprecise information in group multicriteria decisions: a methodology and a GDSS architecture," European Journal of Operational Research, vol. 160, no. 2, pp. 291-307, 2005.

[71] J. P. Lewis and A. Traill, Statistics Explained, AddisonWesley, Harlow, UK, 1999.

[72] C. N. Madu, "A quality confidence procedure for GDSS application in multicriteria decision making," IIE Transactions, vol. 26, no. 3, pp. 31-39, 1994.

[73] D. Bouyssou, M. Pirlot, and P. Vincke, "A general model of preference aggregation," in Essays in Decision Making, M. H. Karwan, J. Spronk, and J. Wallenius, Eds., Springer, Heidelberg, Germany, pp. 120-134, 1997.

[74] J.-H. Chen, "Counseling evaluation and transformation of test performance for the waste electrical and electronic appliance system," Technical Report, Report number: EPA99-HA14-03-A122, Master thesis, Environmental Protection Administration, Taiwan, Republic of China, 2011.

[75] Y.-S. Lee and H.-S. Shih, "Incremental analysis for generalized TODIM," Central European Journal of Operations Research, vol. 24, no. 4, pp. 901-922, 2016.

[76] C. W. Churchman, R. L. Ackoff, and E. L. Arnoff, Introduction to Operations Research, Wiley, Oxford, UK, 1957.

[77] B. Mareschal, "Weight stability intervals in multicriteria decision aid," European Journal of Operational Research, vol. 33, no. 1, pp. 54-64, 1988.

[78] S. Eppe and Y. De Smet, "An adaptive questioning procedure for eliciting PROMETHEE IIs weight parameters," Technical Report No. TR/SMG/2012-002, Université Libre de Bruxelles, City of Brussels, Belgium, 2012.

[79] A. T. de Almeida-Filho, T. R. N. Clemente, D. C. Morais, and A. T. De Almeida, "Preference modeling experiments with surrogate weighting procedures for the PROMETHEE method," European Journal of Operational Research, vol. 264, no. 2, pp. 453-461, 2018.

[80] H. F. Maghrabie, Y. Beauregard, and A. Schiffauerova, "Multi-criteria decision making problems with unknown weight information under uncertain evaluations," Computers \& Industrial Engineering, vol. 133, pp. 131-138, 2019.

[81] K. J. Arrow, Social Choice and Individual Values, Wiley, New York, NY, USA, 2nd. edition, 1963.

[82] F. Bezerra, P. Melo, and J. P. Costa, "Visual and interactive comparative analysis of individual opinions: a group 
decision support tool," Group Decision and Negotiation, vol. 23, pp. 101-125, 2014.

[83] D. Ben-Arieh and T. Easton, "Multi-criteria group consensus under linear cost opinion elasticity," Decision Support Systems, vol. 43, no. 3, pp. 713-721, 2007.

[84] A. Mahmoudi, S. Sadi-Nezhad, and A. Makui, "A hybrid fuzzy-intelligent system for group multi-attribute decision making," International Journal of Fuzzy Systems, vol. 18, no. 6, pp. 1117-1130, 2016.

[85] A. Radojevic, S. Petrovic, and D. Radojevic, "A fuzzy approach to preference structure in multicriteria ranking," International Transactions in Operational Research, vol. 4, no. 5-6, pp. 419-430, 1997.

[86] J. Geldermann, T. Spengler, and O. Rentz, "Fuzzy outranking for environmental assessment. Case study: iron and steel making industry," Fuzzy Sets and Systems, vol. 115, no. 1, pp. 45-65, 2000.

[87] M. Goumas and V. Lygerou, "An extension of the PROMETHEE method for decision making in fuzzy environment: ranking of alternative energy exploitation projects," European Journal of Operational Research, vol. 123, no. 3, pp. 606-613, 2000.

[88] A. S. Fernández-Castro and M. Jiménez, "PROMETHEE: an extension through fuzzy mathematical programming," Journal of the Operational Research Society, vol. 56, no. 1, pp. 119-122, 2005.

[89] K. Zhang, C. Kluck, and G. Achari, "A comparative approach for ranking contaminated sites based on the risk assessment paradigm using fuzzy PROMETHEE," Environmental Management, vol. 44, no. 5, pp. 952-967, 2009.

[90] W.-x. Li and B.-y. Li, "An extension of the Promethee II method based on generalized fuzzy numbers," Expert Systems with Applications, vol. 37, no. 7, pp. 5314-5319, 2010.

[91] H. Liao and Z. Xu, "Multi-criteria decision making with intuitionistic fuzzy PROMETHEE," Journal of Intelligent \& Fuzzy Systems, vol. 27, no. 4, pp. 1703-1717, 2014.

[92] E. Celik and A. Taskin Gumus, "An outranking approach based on interval type-2 fuzzy sets to evaluate preparedness and response ability of non-governmental humanitarian relief organizations," Computers \& Industrial Engineering, vol. 101, pp. 21-34, 2016.

[93] R. K. Ahuja, T. L. Magnanti, and J. B. Orlin, Network Flows: Theory, Algorithms, and Applications, Prentice-Hall, Englewood Cliffs, NJ, USA, 1993.

[94] S. A. Cook, "An overview of computational complexity," Communications of the ACM, vol. 26, pp. 401-408, 1983.

[95] M. S. Bazaraa, J. J. Jarvis, and H. D. Sherali, Linear Programming and Network Flows, Wiley, New York, NY, USA, 2010.

[96] D. L. Olson, "Review of empirical studies in multiobjective mathematical programming: subject reflection of nonlinear utility and learning," Decision Sciences, vol. 23, no. 1, pp. 1-20, 1992.

[97] R. Lourenzutti, R. A. Krohling, and M. Z. Reformat, "Choquet based TOPSIS and TODIM for dynamic and heterogeneous decision making with criteria interaction," Information Sciences, vol. 408, pp. 41-69, 2017.

[98] J. Yu and M.-S. Yang, "A generalized fuzzy clustering regularization model with optimality tests and model complexity analysis," IEEE Transactions on Fuzzy Systems, vol. 15, no. 5, pp. 904-915, 2007.

[99] L. Wang, H. Garg, and N. Li, "Pythagorean fuzzy interactive Hamacher power aggregation operators for assessment of express service quality with entropy weight," Soft Computing, vol. 25, no. 2, pp. 973-993, 2021.

[100] S.-J. Lin, "The impacts of the risk attitudes and thresholds of the decision makers on decision results," Master Thesis, Taichung: Department of Industrial Engineering and Management, Master thesis, Chaoyang University of Technology, Taiwan, Republic of China, 2011. 